\title{
Buoyancy-driven convective heat transfer from a semi-circular cylinder for various confinements
}

\author{
RAKESH KUMAR GUPTA, AVINASH CHANDRA*(D) and RAJ KUMAR GUPTA
}

Department of Chemical Engineering, Thapar Institute of Engineering and Technology, Patiala 147004, India e-mail: avichiitk@yahoo.com

MS received 19 August 2017; revised 8 May 2018; accepted 29 May 2018; published online 5 October 2018

\begin{abstract}
Buoyancy-driven convective heat transfer from a semi-circular cylinder for various confinements has been studied using numerical simulations for wide ranges of parameters, Reynolds numbers $(1 \leq R e \leq 50)$, Richardson numbers $(0 \leq R i \leq 2)$, Prandtl numbers $(0.7 \leq \operatorname{Pr} \leq 50)$ and confinement ratios $(0.2 \leq \beta \leq 0.8)$. A hot semi-circular cylinder is symmetrically kept in a $2 \mathrm{D}$ rectangular confinement. The circular side of the cylinder faces the upstream flow and the fluid flows against gravity in the channel. The governing equations are numerically solved using FLUENT and the results obtained are presented in the form of isotherms, streamlines, pressure coefficients, drag coefficients, Nusselt numbers, etc. The highest value of pressure coefficient increases with blockage ratio for all cases. The drag coefficient decreases with $R e$ and shows complex phenomena with change in $R i$ and blockage ratio of the channel. Pressure drag has contributed more as compared with viscous drag in all cases. The curved surface showed more heat transfer than the flat surface of the semi-circular cylinder. The value of $\beta$ also has great influence at large value of Peclect numbers $(=2500)$. Overall average heat transfer in terms of average Nusselt number is a function of $R i, \operatorname{Re}, \operatorname{Pr}$ and $\beta$.
\end{abstract}

Keywords. Channel flow; mixed convection; semi-circular cylinder; CFD.

\section{Introduction}

Momentum and heat transfer studies of confined bluff bodies have much importance in modern applications like cooling of electronic components, drying of food stuffs, solar thermal extraction systems, flow meters, building works, nuclear reactors, natural circulation boilers, processing of fibrous suspensions, removal of oversized particles from coating suspensions and design of novel heat exchanging devices $[1,2]$. The widely studied bluff bodies are cylinders of various cross-sections such as circular, square, triangular, elliptical, semi-circular, etc. It is well known that most heat exchangers use circular cross-section tubes as essential part of their construction. The phenomenon of heat transfer taking place through the surface of circular tubes is an example of the study of heat transfer and flow over a circular bluff body. In the context of geometry, a semi-circular cylinder occupies half space as compared with circular cylinders. In case of semi-circular cylinders, the presence of sharp corners and rear flat surface provides additional mixing; hence the heat transfer increases. Among different cross-sections of cylindrical bluff bodies, semi-circular cylinder gained importance in the recent past because of its suitability for compact heat exchangers in modern applications and its shape allows

*For correspondence economical use of space [3]. Moreover, a semi-circular cylinder has the advantage of higher average Nusselt number as compared with a circular cylinder $[4,5]$.

Detailed reviews of flow and heat transfer from different types of bluff bodies are available in literature [6-8]. When a flow passes over a bluff body, the flow gets separated and trailing wakes are formed. The flow separation and wake kinematics largely depend on body geometry, flow regime, fluid properties, confinement and body forces. Complex flow behaviours are usually seen with gravity at low and/or moderate Reynolds numbers (laminar and/or transition flow regime). Fundamentally, natural convection is always present with forced convection; however, its contribution may be small. In case of low and/or moderate Reynolds numbers, natural and forced convection phenomena are present and this is termed as mixed convection heat transfer. The relative contribution of natural convection to forced convection is usually measured by the value of a non-dimensional parameter known as Richardson number $(R i)$.

A few experimental investigations on heat transfer have been reported in some research works [9-11], with addition of buoyancy in different flow regimes over cylinders. One [9] of these research works experimentally studied heat transfer from circular cylinders in the range of $R e=$ $100-3000$ and $G r=25000-300000$ at blockage ratio $(\beta)=0.047,0.094$. They concluded that heat transfer rates were dependent on a non-dimensional parameter $\left(G r / R e^{2}\right)$, 
for the entire range of conditions studied. They extended this work for various angles $\left(0^{\circ}, 90^{\circ}, 135^{\circ}\right.$ and $\left.180^{\circ}\right)$ and forced flow and buoyant flow [10]. For angles of $0^{\circ}$ and $90^{\circ}$, the heat transfer was reported to increase with rise in buoyance forces. Another study [11] investigated influence of buoyancy on wake formed behind hot cylinders of different shapes for Reynolds number ranges of 53-110 and 87-118. An experimental investigation on forced convection momentum and heat transfer over a semi-circular cylinder is also available in literature [12], wherein momentum and heat transfer to air from the cylinder at different orientations in the range of $2.2 \times 10^{3}$ $\leq R e \leq 4.5 \times 10^{4}$ is studied. The average Nusselt number $\left(N u_{\text {avg }}\right)$ was reported to be the maximum for the arrangement with curved surface of cylinder facing flow as compared with other orientations at different angles of attack of flow to curved surface of the cylinder. $N u_{\text {avg }}$ was found to increase with value of Reynolds number in all configurations, as per the well-known power law.

Moreover, numerous two-dimensional numerical investigations have been reported in previous years related to flow over and heat transfer from bluff bodies. These works address flow and heat transfer with various geometries with the influence of aiding/opposing buoyancy. Some of these works studied unconfined bluff bodies [13-18] and others studied confined bluff bodies [3, 19-24]. Detailed reviews on circular cylinders are already reported in literature [6, 7]. One of the numerical study [20] on mixed convection for similar configuration concluded delaying of flow separation from cylinder and shortening of wake behind cylinder due to rise in value of Richardson number or blockage ratio. Moreover, they observed reverse flow near to wall at much higher values of Richardson number. Another researcher [19] observed same intensity of forced and free convective flow at $R i=36, \beta=0.167$ and value of $N u_{\text {avg }}$ was also reported to rise with value of $R e$ [19, 20] or $R i$ [20].

Numerical simulations were also carried out for confined square cylinder [1, 23, 24]. Flow separation and wake formation at rear side of cylinder were observed due to increase in Reynolds number and wake size was reduced with increase in Richardson number [24]. One of these studies [23] observed the change of flow behaviour from unsteady vortex shedding to steady vortex with increase in Richardson number. The value of $C_{D}$ was seen to be higher with either decrease in Reynolds number or increase in blockage ratio or rise in Richardson number [24]. The value of $N u_{\text {avg }}$ was found to rise with increase in Reynolds number [23] or blockage ratio [1, 23] or Richardson number $[1,24]$.

Semi-circular cylinders were also considered by a few researchers to visualize phenomena of flow and heat transfer in unconfined space [25] as well as in confined space [2, 3, 26]. In a mixed convection study from unconfined semi-circular cylinder [25], drag coefficient was observed to increase with either decrease of value of $R e$ or increase in value of $R i$. The value of $N u$ at surface of cylinder was found to be the maximum at corners of the cylinder at low $R e$ and shifted towards front stagnation point with increase in Reynolds number. Value of $N u_{\text {avg }}$ increased with increase in value of any of three, viz., $R e, \operatorname{Pr}$ and $R i$. In another study [2], air flow and forced convective heat transfer characteristics from a confined semi-circular cylinder were examined. In this study, flow separation and wake formation were observed with increase of Reynolds number and these phenomena got delayed with increase in blockage ratio. The wake size downstream of cylinder increased at either higher values of $R e$ or lower values of $\beta$. Moreover, in a similar study [25] of confined semi-circular cylinder, steady flow was observed to change into time periodic pattern for $R e=69-70$. Individual and drag coefficients increased due to either decrease in value of $R e$ or increase in value of $\beta$ [2]. Ratio of individual drag coefficients $\left(C_{D P} / C_{D F}\right)$ increased due to increase in value of either $R e$ or $\beta$. The value of local Nusselt number on cylinder surface increased due to increase in either Reynolds number or blockage ratio. The value of $N u_{\text {avg }}$ increased with increase in $R e$ only for $R e>5$ but mixed patterns were observed in the range of $1 \leq R e \leq 5$. In a different study of confined semi-circular cylinder [3], value of $N u_{\text {avg }}$ of confined semi-cylinder cylinder was found to be more as compared with the unconfined one and increased with increase in blockage ratio of confinement. In a previous study [26] of confined cylinder, the average Nusselt number $\left(N u_{a v g}\right)$ sharply increased due to rise of value of Pr.

Many numerical studies are available concerning twodimensional momentum and heat transfer from confined cylinders of either circular or square geometry with aiding/opposing buoyancy. Furthermore, one similar research work [25] is also reported on unconfined semicircular cylinder with addition of buoyancy. Although, three different research studies [2, 3, 26] are reported on confined semi-circular cylinders, they are without addition of buoyancy. In one of these studies [2], forced convection has been considered, which is far different from the present study of mixed convection. Another study [3] considered a similar system for power-law fluids. One further study [25] presented the vortex shedding results for similar configurations reported [2, 3]. In these three studies, confined semi-circular configuration was used for forced convection heat transfer without considering gravity. However, in our present case, flow against gravity has been considered with varying confinement, which has never been explored in the literature to the best of our knowledge. No two-dimensional numerical simulation of buoyancy-aided heat convection and fluid flow characteristic past a semi-circular cylinder is available in the literature. Therefore, the present work is targeted to fill such a gap of 2D mixed convection momentum and heat transfer in the area of numerical transport phenomena. 


\section{Problem specification}

A two-dimensional numerical simulation of momentum and heat transfer from a cylinder is considered. A long confined hot semi-circular cylinder is used and schematic of the problem is given in figure 1. A cylinder with diameter $D$ has been kept inside a straight confinement of width $L$. The cylinder has distance $M$ from inlet section and $N$ from outlet section. The cylinder (maintained at constant value of wall temperature $T_{w}$ ) is kept in a channel such that the curved side of cylinder faces the oncoming flow.

The confinement of channel is represented in terms of a dimensionless parameter, blockage ratio $(\beta)$, which ranges from 0.2 to 0.8 in the present study. Many previous studies $[2,3]$ used blockage ratio in the range of $0.2-0.5$, which is currently extended up to 0.8 to provide results in a larger practical range. A Newtonian, incompressible fluid at constant temperature of $T_{\infty}\left(T_{\infty}<T_{w}\right)$ flows between adiabatic walls of the channel. The flow is considered as steady and laminar, and has a parabolic velocity profile at the inlet section [23]. The forced flow is also aided by buoyant flow, developed due to density variation in the fluid, which is in the same direction of the forced flow. Thermo-physical fluid properties are considered as constant with respect to variation in temperature. The fluid density $(\rho)$ is expected to vary due to temperature and included to

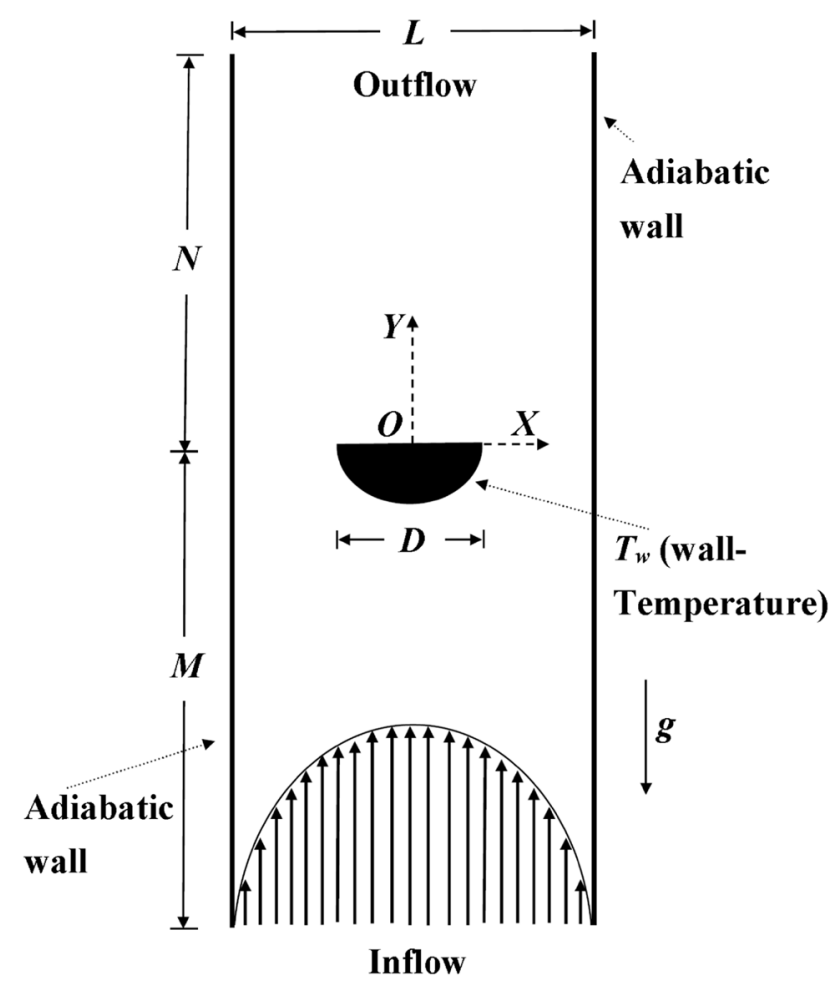

$$
\left(V_{\infty}, T_{\infty}\right)
$$

Figure 1. Schematic of flow over confined heated semi-circular cylinder. $y$-component of momentum equation. Presently, the density variation can be incorporated through the Boussinesq approximation $\rho=\rho_{\infty}\left[1-\beta_{V}\left(T-T_{\infty}\right)\right]$ (proposed by $\mathrm{J} \mathrm{V}$ Boussinesq), like those with lower temperature differences (here, $T_{w}-T_{\infty}=1$ ). Due to the small temperature difference, it is reasonable to assume that all other thermophysical properties are constant. It is well accepted that viscous dissipation effects are important in thermal energy equation for a flow with large velocity gradients [23]. In the present study, flow currents have small velocity gradients due to low values of Reynolds number and weak buoyancy in the flow. Therefore, viscous dissipation is not important and can be ignored in energy equation for the present case. There are different literatures $[1,20]$ in which the viscous dissipation is neglected for an approximately similar range of governing parameters. This assumption is also aligned with one of the previous study of semi-circular cylinders for similar sets of $R e, P r$ and $R i$ as in case of present simulation. The dimensionless governing equations [27] for the present situation are given here in Eqs. (1)-(4).

Mass conservation:

$$
\frac{\partial u}{\partial x}+\frac{\partial v}{\partial y}=0
$$

$x$-momentum conservation:

$$
u \frac{\partial u}{\partial x}+v \frac{\partial u}{\partial y}=-\frac{\partial p}{\partial x}+\frac{1}{R e}\left(\frac{\partial^{2} u}{\partial x^{2}}+\frac{\partial^{2} u}{\partial y^{2}}\right)
$$

$y$-momentum conservation:

$$
u \frac{\partial v}{\partial x}+v \frac{\partial v}{\partial y}=-\frac{\partial p}{\partial y}+\frac{1}{R e}\left(\frac{\partial^{2} v}{\partial x^{2}}+\frac{\partial^{2} v}{\partial y^{2}}\right)+R i . \theta
$$

Energy conservation:

$$
u \frac{\partial \theta}{\partial x}+v \frac{\partial \theta}{\partial y}=\frac{1}{R e \cdot \operatorname{Pr}}\left(\frac{\partial^{2} \theta}{\partial x^{2}}+\frac{\partial^{2} \theta}{\partial y^{2}}\right)
$$

where all dimensionless variable are defined as follows:

$$
\begin{aligned}
x & =X / D, y=Y / D, u=U / V_{\infty}, v=V / V_{\infty}, p=P / \rho V_{\infty}^{2}, \\
\theta & =\left[\left(T-T_{\infty}\right) /\left(T_{w}-T_{\infty}\right)\right]
\end{aligned}
$$

The governing equations (1)-(4) are subject to the following physical boundary conditions.

At flow inlet, the fluid enters at constant temperature $\left(T_{\infty}\right)$ and has a fully developed parabolic velocity profile. Hence, the boundary conditions at inlet can be written as

$$
u=0, v=1.5(1-2 \beta|x|)^{2}, \theta=0 .
$$

Adiabatic walls are no-slip solid boundaries and adiabatic situation exists throughout the confinement. Hence

$$
u=0, v=0, \partial \theta / \partial x=0 .
$$


Cylinder surface is also a solid surface, and no-slip condition is used there. The surface is maintained at constant wall temperature $T_{w}$. Hence, the boundary conditions are

$$
u=0, v=0, \theta=1 .
$$

Flow at the exit is fully developed conditions. This considers zero diffusion of all variables along the flow at the exit and has similarity with homogeneous Neumann boundary conditions. However, any of the properties still can show lateral gradients in flow at the exit. Hence, exit conditions is approximated as follows

$$
\partial \varphi / \partial y=0, \text { where } \varphi=u, v \text { and } \theta \text {. }
$$

At the line of symmetry: for the present operating conditions, flow behaviour must be laminar and symmetric on middle plane $x=0$. Hence, the symmetry boundary conditions is applied as follows:

$$
u=0, \partial v / \partial x=0, \partial \theta / \partial x=0 .
$$

The values of flow and temperature field variables $(u, v, p$ and $\theta$ ) have been obtained after solving governing equations (1)-(4). These variables are further used to calculate different practically important parameters like total drag coefficient $\left(C_{D}\right)$, pressure drag coefficient $\left(C_{D P}\right)$, friction (viscous) drag coefficient $\left(C_{D F}\right)$, pressure coefficient $\left(C_{P}\right)$, local Nusselt number $(\mathrm{Nu})$ and average Nusselt number $\left(N u_{a v g}\right)$, as defined in Eqs. (5)-(10):

$$
\begin{gathered}
C_{D}=\frac{F_{D}}{(1 / 2) \rho V_{\infty}^{2} D}=C_{D P}+C_{D F}, \\
C_{D P}=\frac{F_{D P}}{(1 / 2) \rho V_{\infty}^{2} D}, \\
C_{D F}=\frac{F_{D F}}{(1 / 2) \rho V_{\infty}^{2} D}, \\
C_{P}=\frac{P_{s}-P_{\infty}}{(1 / 2) \rho V_{\infty}^{2}} \\
N u=-\frac{\partial \theta}{\partial n_{s}} \\
N u_{a v g}=\frac{1}{S} \int N u . d S .
\end{gathered}
$$

\section{Numerical methodology}

The non-uniform hybrid grids generated in ANSYS FLUENT are used for numerical simulation of the present problem. To capture the field gradient near the semi-circular cylinder, fine grids are generated and used near the cylinder surface. The two-dimensional steady, laminar, coupled solver in ANSYS FLUENT has been deployed to obtain solutions of governing equations. The convective terms of Eqs. (2)-(4) are discretized by a second order upwind scheme. Coupling of pressure-velocity is done using the SIMPLE scheme. The standard Boussinesq approximation for density variation is used and other physical properties are kept constant. The iterations are solved by the GaussSiedel method in connection to multi-grid method to evaluate governing equations. Numerical tolerance limits are taken as $10^{-8}$ for residuals of Eqs. (1)-(3) and as $10^{-15}$ for residual of Eq. (4). Computational time has been reported to increase with increase in the value of $R i$ to meet the identical degree of solution convergence. It is obvious that mixed convection problem has one extra variable, $R i$, in $y$ momentum equation, which increases complexity in simulation and desired convergence. Domain and grid-independence simulation runs are also conducted, so that the ultimate solution is independent of choice of domain and mesh size. Domain- and grid-independent studies are a trade-off between high computational resources (due to large domain size and ultrafine grids) and accuracy of the results. Inlet boundary domain-independence tests are carried out in the range of values of $m(=M / D)$ as 25-50 for limiting values of dimensionless governing parameters (i.e., $\operatorname{Re}=1,50, \operatorname{Pr}=$ $0.7,50$ and $R i=0,2$ ). The inlet boundary domain is found to be optimum at $m=30$. Further, outlet boundary domain is also optimized in the range of values of $n(=N / D)$ as 30-60 for the same values of $R e, \operatorname{Pr}$ and $R i$ and found to be optimum at $n=40$. The results of domain-independent tests are presented in table 1 . Three different grids (G1-G3) have been used to carry out grid independence at limiting conditions. The details of different grids and simulation results are presented in table 2 . Table 2 clearly shows that percentage difference in values of $C_{D P}, C_{D F}, C_{D}, N u_{a v g}$ for grid $\mathrm{G} 2$ and $\mathrm{G} 3$ have been found to be about $1 \%$ for all conditions. Further refinement of the grid will lead to high computational time without any appreciable change in the results. Therefore, grid G2 is considered as the optimum grid for current work and also shown in figure 2.

\section{Results and discussion}

The obtained numerical outcomes are presented and discussed in this section. It is always mandatory to ensure the reliability of solution technique with choice of numerical parameters to be used in simulation experiments. Two previous works $[19,25]$ have been selected to validate current numerical scheme for heat transfer from cylinders. The first work is on a confined cylinder in the absence as well as presence of buoyance forces, whereas the second is on a semi-circular cylinder in the presence of buoyance forces. These validation works support heat transfer simulation for both semi-circular cylinder and confined cylinder in the presence of buoyance forces. The results of validation work are presented in table 3 . 
Table 1. Results of domain-independence tests.

\begin{tabular}{|c|c|c|c|c|c|c|c|c|c|c|c|}
\hline$m$ & $n$ & $\beta$ & $R e$ & $R i$ & $\operatorname{Pr}$ & $C_{D P}$ & Change $(\%)$ & $C_{D}$ & Change (\%) & $N u_{\text {avg }}$ & Change $(\%)$ \\
\hline \multicolumn{12}{|c|}{ Inlet domain-independence results } \\
\hline 25 & 50 & 0.25 & 1 & 0 & 0.7 & 19.65 & - & 28.24 & - & 0.838 & - \\
\hline 30 & 50 & 0.25 & 1 & 0 & 0.7 & 19.68 & 0.15 & 28.25 & 0.4 & 0.838 & 0 \\
\hline 40 & 50 & 0.25 & 1 & 0 & 0.7 & 19.61 & 0.36 & 28.22 & 0.11 & 0.838 & 0 \\
\hline 25 & 50 & 0.25 & 50 & 2 & 0.7 & 2.08 & - & 2.73 & - & 5.242 & - \\
\hline 30 & 50 & 0.25 & 50 & 2 & 0.7 & 2.09 & 0.48 & 2.74 & 0.37 & 5.257 & 0.29 \\
\hline 40 & 50 & 0.25 & 50 & 2 & 0.7 & 2.18 & 4.30 & 2.75 & 0.36 & 5.277 & 0.38 \\
\hline \multicolumn{12}{|c|}{ Outlet domain-independence results } \\
\hline 30 & 30 & 0.25 & 1 & 0 & 0.7 & 19.65 & - & 28.26 & - & 0.8380 & - \\
\hline 30 & 40 & 0.25 & 1 & 0 & 0.7 & 19.74 & 0.46 & 28.27 & 0.04 & 0.8379 & 0.01 \\
\hline 30 & 50 & 0.25 & 1 & 0 & 0.7 & 19.73 & 0.05 & 28.27 & 0.00 & 0.8379 & 0.00 \\
\hline 30 & 30 & 0.25 & 50 & 2 & 50 & 2.090 & - & 2.740 & - & 5.257 & - \\
\hline 30 & 40 & 0.25 & 50 & 2 & 50 & 2.090 & 0.00 & 2.740 & 0.00 & 5.255 & 0.04 \\
\hline 30 & 50 & 0.25 & 50 & 2 & 50 & 2.090 & 0.00 & 2.740 & 0.00 & 5.254 & 0.02 \\
\hline
\end{tabular}

Table 2. Results of domain-independence tests.

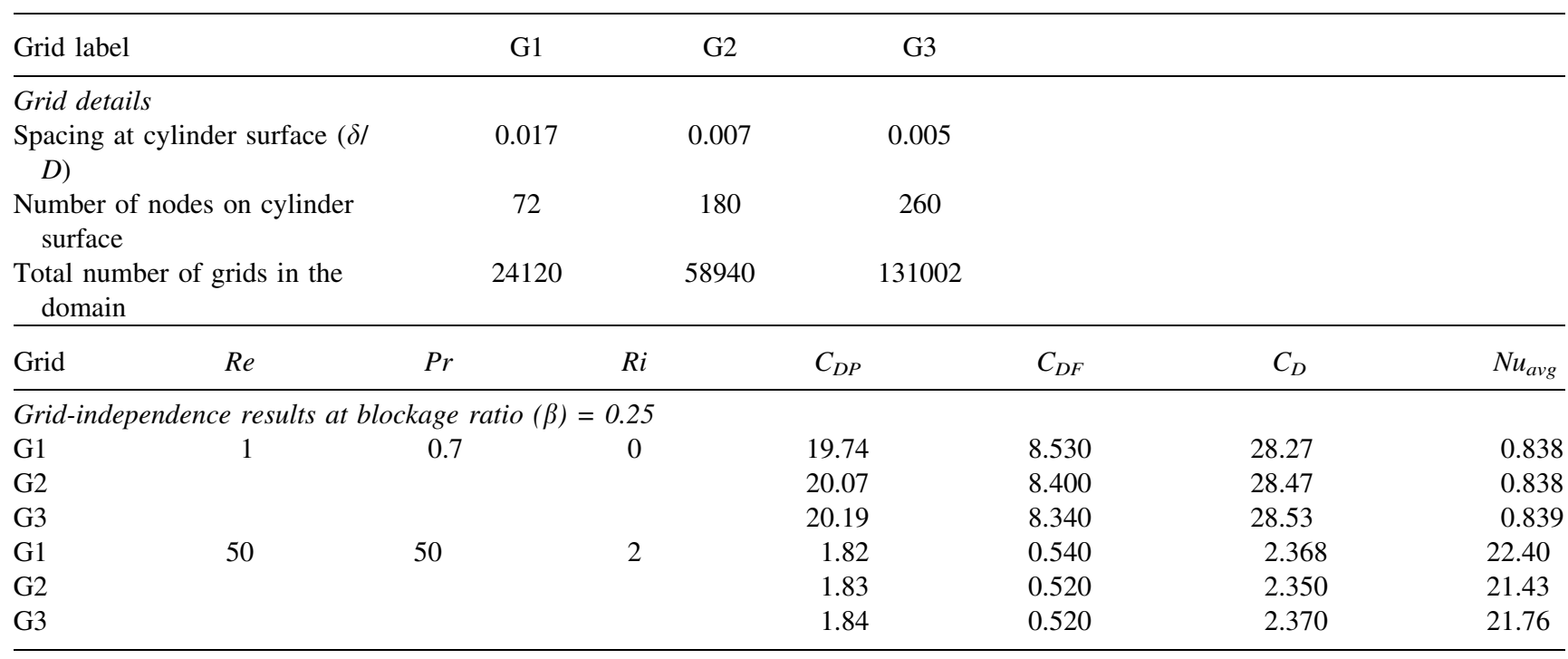

As per table 3, validation results have maximum deviations up to $3.5 \%$ which are acceptable. On the basis of discussion of above validation work, present results have accuracy within $\pm 4 \%$. Therefore, the used numerical methodology can be considered as reliable and accurate within $4 \%$ for numerical work of flow over a confined semicircular cylinder and its thermal characteristics on addition of buoyancy. After getting the confidence with the present numerical methodology, this numerical scheme is used to study mixed convection from confined semi-circular cylinder in the interval of Reynolds number of 1-50, Prandtl number of 0.7-50, Richardson number of 0-2 and blockage ratio of $0.2-0.8$. The highest $\operatorname{Pr}$ value is taken as 50 , considering its practical importance in use of high viscous or high molecular weight fluids in chemical, petroleum- and oil-related engineering application industries [3]. Moreover, the high values of $\operatorname{Pr}$ up to 50 may be shown by food products and light organic oils, etc. For example, the values of $\operatorname{Pr}$ for sucrose solutions, which is considered as one of the food products, are reported in the range of 6.8-49.4 [28]. For light organic fluids, Prandtl number is also reported in the range of 5-50 [29]. The range of $\operatorname{Pr}$ for the present study also is decided as $0.7-50$ based on some previous research works [1, 3, 23].

\subsection{Description of flow}

4.1a Streamline profiles: The flow behaviour around the semi-circular cylinder under confinement is given in terms of streamline profiles (left half) in figures 3-5 at limiting 


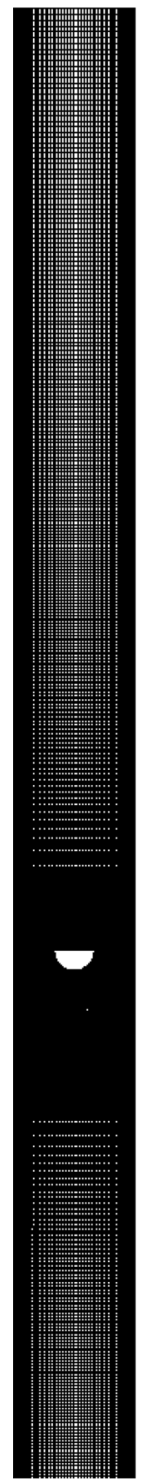

(a)

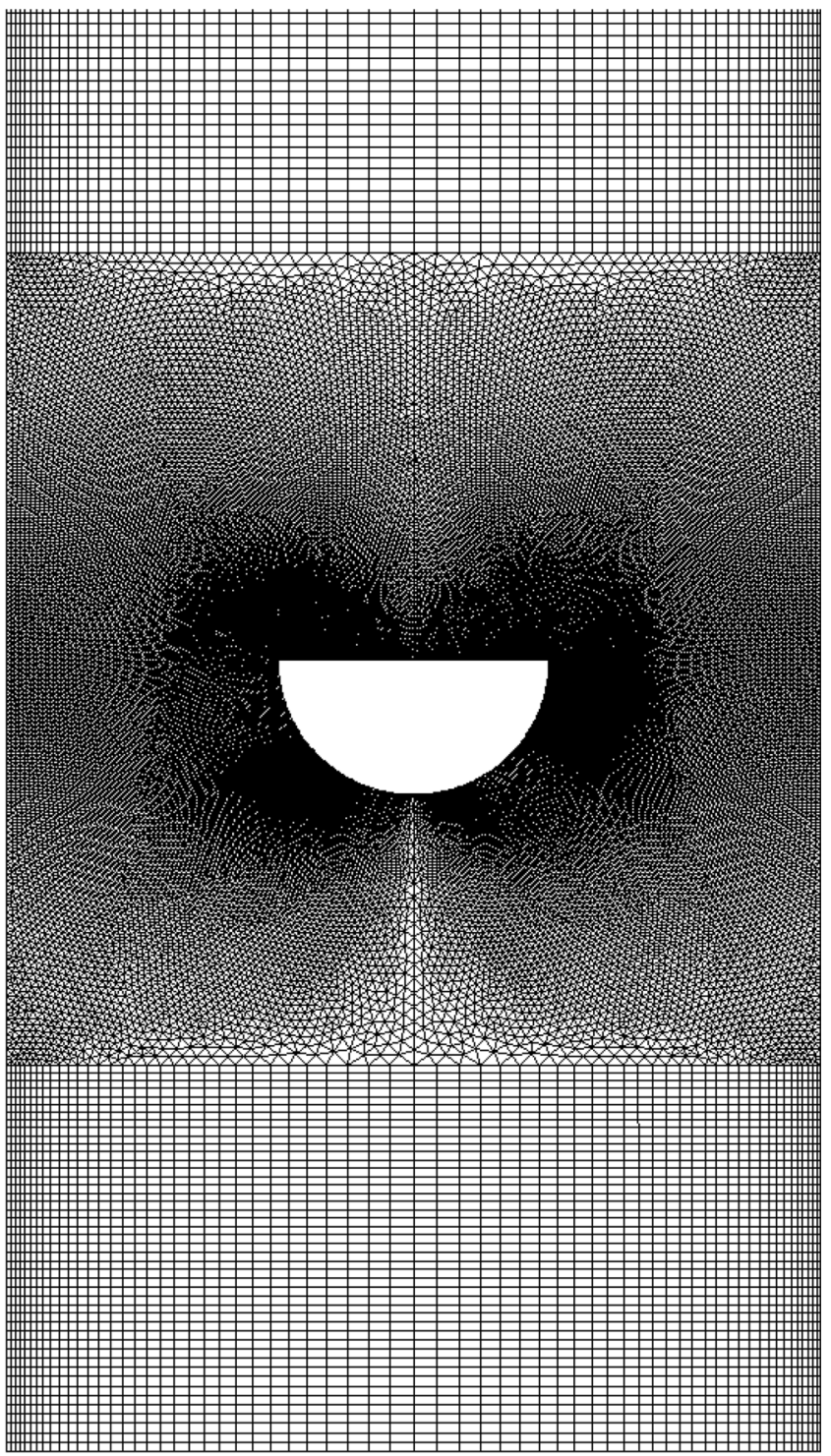

(b)

Figure 2. Grid (G2) used in grid-independence study: (a) full view and (b) zoom view.

Table 3. Results of validation work for Farouk and Guceri [19], Chandra and Chhabra [25].

\begin{tabular}{|c|c|c|c|c|c|}
\hline & $\operatorname{Re}$ & $\operatorname{Pr}$ & $C_{D P}$ & $C_{D}$ & $N u_{\text {avg }}$ \\
\hline \multicolumn{6}{|c|}{ Forced convection from semi-circular cylinder } \\
\hline Chandra and Chhabra [25] & 20 & 0.7 & 1.313 & 1.993 & 3.64 \\
\hline \multirow[t]{2}{*}{ Present work (\% deviation) } & & & $1.315(0.15 \%)$ & $1.995(0.1 \%)$ & $3.52(3.3 \%)$ \\
\hline & & & $\operatorname{Pr}$ & $R i$ & $N u_{\text {avg }}$ \\
\hline \multicolumn{6}{|c|}{ Mixed convection from confined circular cylinder } \\
\hline Farouk and Guceri [19] & & & 0.7 & 4.12 & 6.63 \\
\hline Present work (\% deviation) & & & & & $6.40(3.5 \%)$ \\
\hline
\end{tabular}



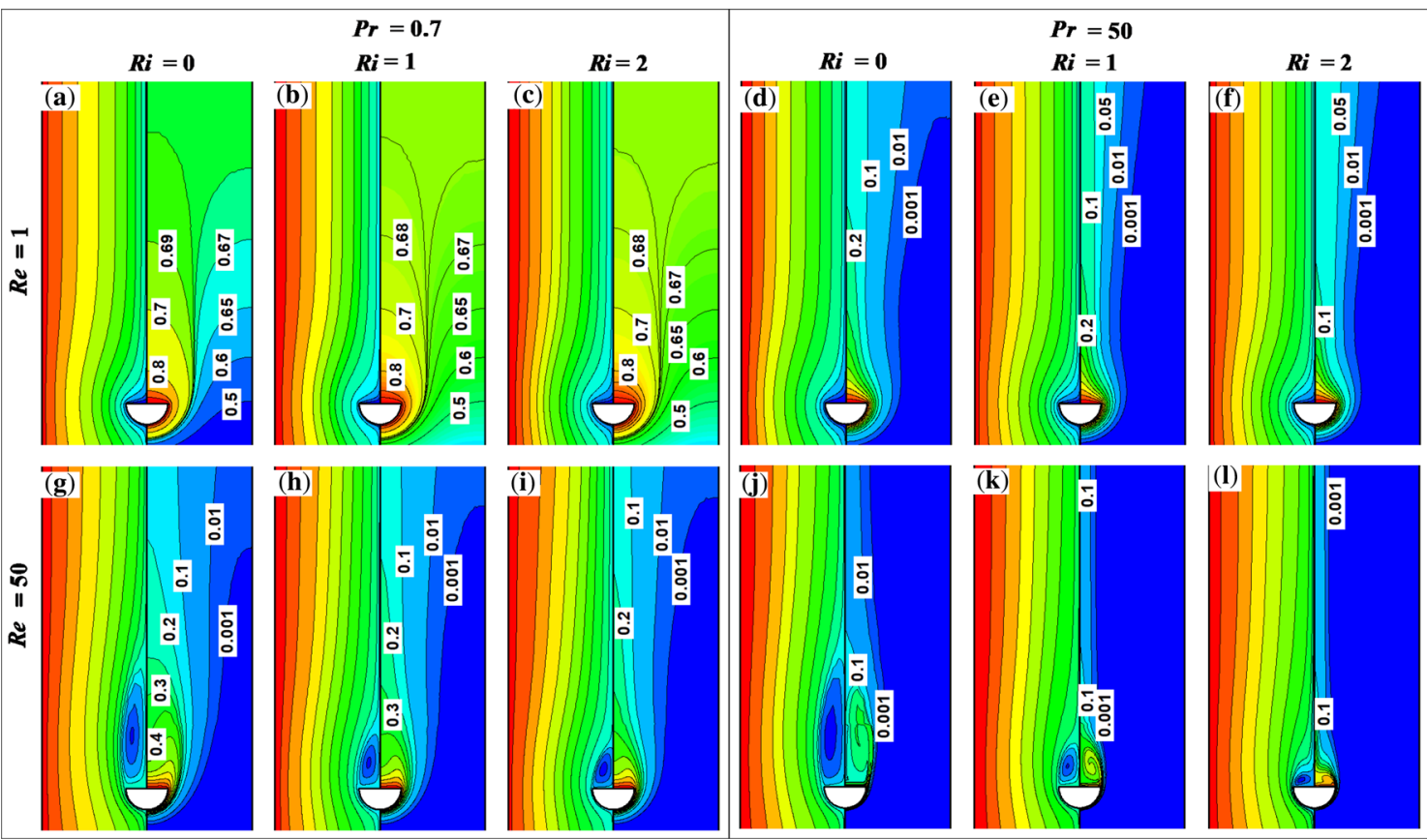

Figure 3. Streamlines (left half) and isotherms (right half) profiles at $\beta=0.2$ for different values of $\operatorname{Re}, \operatorname{Pr}$ and $\operatorname{Ri}[(\mathbf{a}) \operatorname{Re}=1, \operatorname{Pr}=0.7$, $R i=0,(\mathbf{b}) \operatorname{Re}=1, \operatorname{Pr}=0.7, R i=1,(\mathbf{c}) \operatorname{Re}=1, \operatorname{Pr}=0.7, R i=2,(\mathbf{d}) \operatorname{Re}=1, \operatorname{Pr}=50, R i=0,(\mathbf{e}) \operatorname{Re}=1, \operatorname{Pr}=50, R i=1,(\mathbf{f}) \operatorname{Re}=1$, $\operatorname{Pr}=50, R i=2,(\mathbf{g}) \operatorname{Re}=50, \operatorname{Pr}=0.7, R i=0,(\mathbf{h}) \operatorname{Re}=50, \operatorname{Pr}=0.7, R i=1$, (i) $\operatorname{Re}=50, \operatorname{Pr}=0.7, R i=2,(\mathbf{j}) \operatorname{Re}=50, P r=50, R i=0$, (k) $\operatorname{Re}=50, \operatorname{Pr}=50, R i=1$, (l) $\operatorname{Re}=50, \operatorname{Pr}=50, R i=2]$.

values of $R e$ and $\operatorname{Pr}$ for $R i=0,1,2$ and $\beta=0.2,0.33,0.8$. Figures 3-5 clearly show that the flow follows the body contour or it is completely attached to cylinder body at $R e=1$, but symmetric wakes are observed for $R e=50$ at all values of $P r, R i$ and $\beta$. It is a well-established fact $[2,4,25]$ that the flow detaches from rear side of cylinder with increase in Reynolds number and symmetric wakes are also observed. This occurs due to increase in domination of inertial forces over viscous forces. Figure 3 shows that for $R e=1$, no appreciable changes in the streamlines are observed with increase in value of either $R i$ or $P r$ at all values of $\beta$. Further, for the set $\operatorname{Re}=50, \beta=0.2$ (figure 3), the wake size has decreased by $67 \%$ and $90 \%$ due to increase in value of $R i$ in the range of $0-2$ at $P r=0.7$ and 50 , respectively. Increase of Richardson number causes increase in inertial force due to addition of buoyance force, which is opposed to pressure force and viscous force acting in the vicinity of semi-circular cylinder. This causes rise in velocity in the wake and shear forces get weakened. This tries to delay flow separation from the cylinder and shorten the wake size [21, 23]. Therefore, increase in Richardson number is responsible for separation delay and reduction in wake size. For another blockage ratio $(\beta)=0.33$, wake size decreases up to $41 \%$ due to increase of $R i$ in the range of $0-1$ and again increases to original wake size (at $R i=0$ ) with increase of $R i$ in the range of 1-2, for all $P r$ considered. The increase in wake size due to increase of Richardson number $(R i=1-2)$ is observed possibly due to mixed effects from buoyance force, wall effect, pressure force and geometry of the semi-circular cylinder. As Richardson number increases $(R i=1-2)$, wake is expected to get delayed and decrease in size. However, due to corners of the semi-circular cylinder, wake separation is not delayed much at $R i=2$. Net flow around the cylinder increases because of combined effect of buoyance force $(R i=2)$ and higher blockage ratio $(\beta=0.33)$ and leads to increase in the wake size. For higher blockage ratio $(\beta)$ of 0.8 , wake size decreases only up to $6 \%$ due to increase of Richardson number for all Prandtl numbers studied here. However, secondary wakes are also observed at $\beta=0.8$ for all values of $\operatorname{Pr}$ and $R i$. At $\beta=0.8$, net flow around cylinder is relatively very high as compared with $\beta=0.25$ and 0.33 . The strong inertial forces are possibly more dominant over buoyance forces and pressure forces and cause a small decrease in the wake size. It is clear from this discussion that increase in value of Richardson number governs streamline profiles and wake region (at $R e=50$ ) of cylinder in a mixed manner depending on values of channel blockage ratio and Prandtl number. Moreover, for $R i=0$ and 1 , the wake size is decreased with increase in value of blockage ratio for all Prandtl numbers studied. Decrease of distance between walls confines and stabilizes the wake and reduces its size at higher blockage ratio. This effect of blockage ratio is seen to be more prominent at $R i=0$ as compared with $R i=1$. For $R i=2$, wake size shows a mixed behaviour with increase in value of $\beta$. Wake size is 

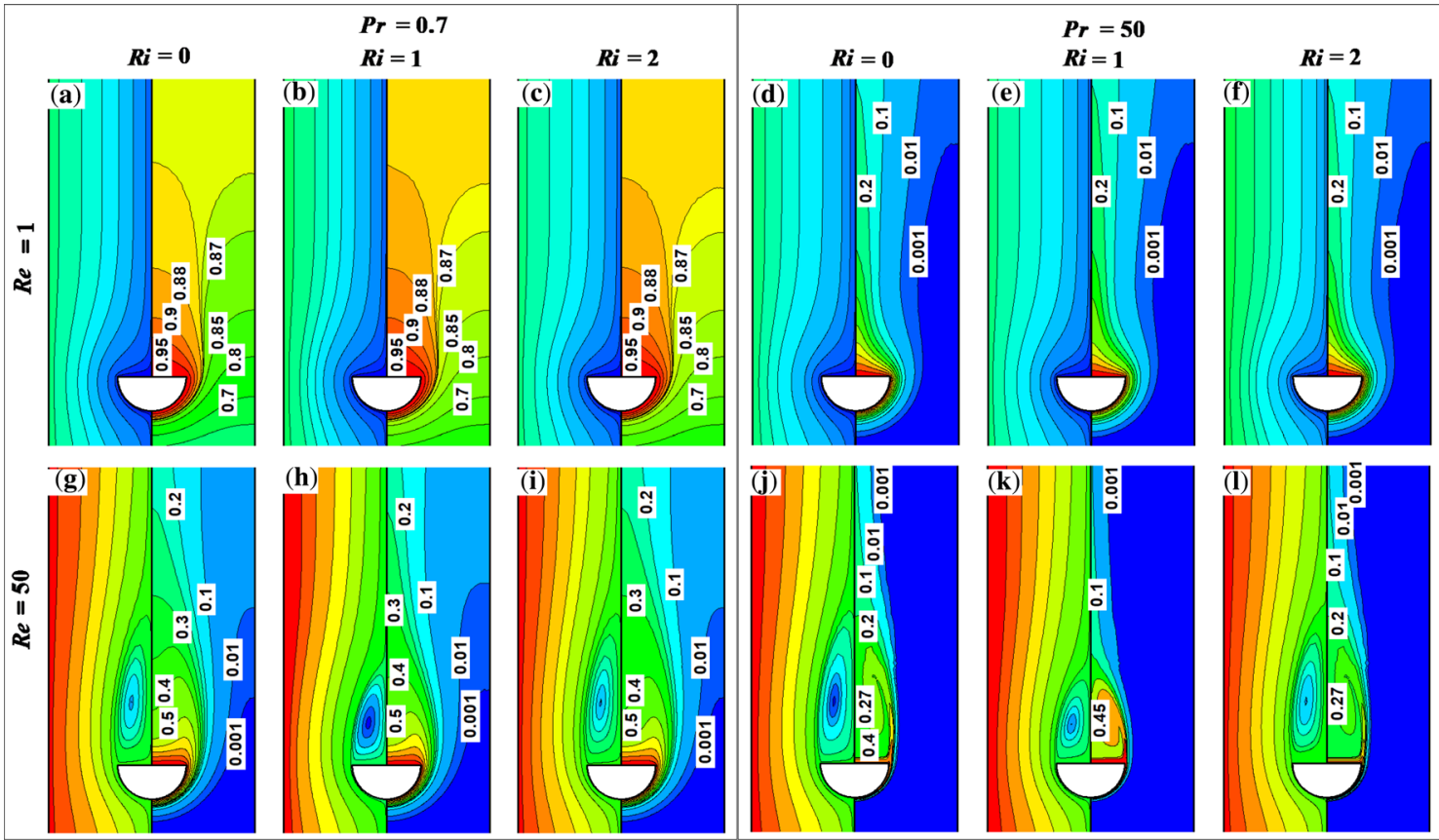

Figure 4. Streamlines (left half) and isotherms (right half) profiles at $\beta=0.33$ for different values of $\operatorname{Re}, \operatorname{Pr}$ and $\operatorname{Ri}[(\mathbf{a}) \operatorname{Re}=1$, $\operatorname{Pr}=0.7, R i=0,(\mathbf{b}) \operatorname{Re}=1, \operatorname{Pr}=0.7, R i=1,(\mathbf{c}) \operatorname{Re}=1, \operatorname{Pr}=0.7, R i=2,(\mathbf{d}) \operatorname{Re}=1, \operatorname{Pr}=50, \operatorname{Ri}=0,(\mathbf{e}) \operatorname{Re}=1, \operatorname{Pr}=50, \operatorname{Ri}=1$, (f) $R e=1, P r=50, R i=2,(\mathbf{g}) \operatorname{Re}=50, \operatorname{Pr}=0.7, R i=0$, (h) $\operatorname{Re}=50, \operatorname{Pr}=0.7, R i=1$, (i) $\operatorname{Re}=50, \operatorname{Pr}=0.7, R i=2,(\mathbf{j}) \operatorname{Re}=50$, $\operatorname{Pr}=50, R i=0$, (k) $\operatorname{Re}=50, \operatorname{Pr}=50, R i=1$, (l) $\operatorname{Re}=50, \operatorname{Pr}=50, R i=2]$.
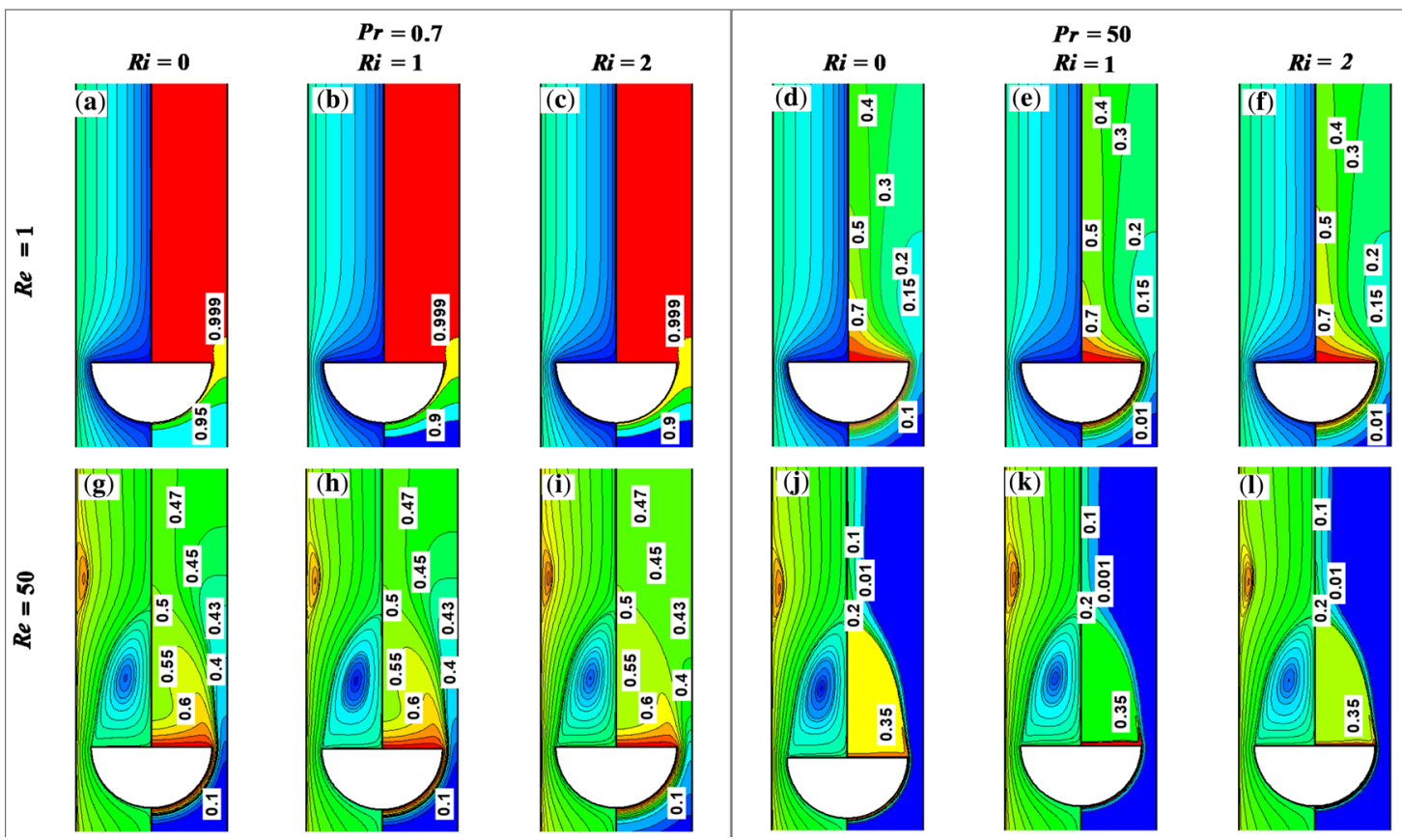

Figure 5. Streamlines (left half) and isotherms (right half) profiles at $\beta=0.8$ for different values of $\operatorname{Re}, \operatorname{Pr}$ and $\operatorname{Ri}[(\mathbf{a}) \operatorname{Re}=1, \operatorname{Pr}=0.7$, $R i=0$, (b) $R e=1, P r=0.7, R i=1$, (c) $R e=1, P r=0.7, R i=2,(\mathbf{d}) \operatorname{Re}=1, \operatorname{Pr}=50, R i=0,(\mathbf{e}) \operatorname{Re}=1, P r=50, R i=1,(\mathbf{f}) \operatorname{Re}=1$, $\operatorname{Pr}=50, R i=2,(\mathbf{g}) \operatorname{Re}=50, \operatorname{Pr}=0.7, R i=0$, (h) $R e=50, \operatorname{Pr}=0.7, R i=1$, (i) $\operatorname{Re}=50, \operatorname{Pr}=0.7, \operatorname{Ri}=2,(\mathbf{j}) \operatorname{Re}=50, P r=50, R i=0$, (k) $R e=50, P r=50, R i=1$, (l) $R e=50, P r=50, R i=2]$. 
(a)

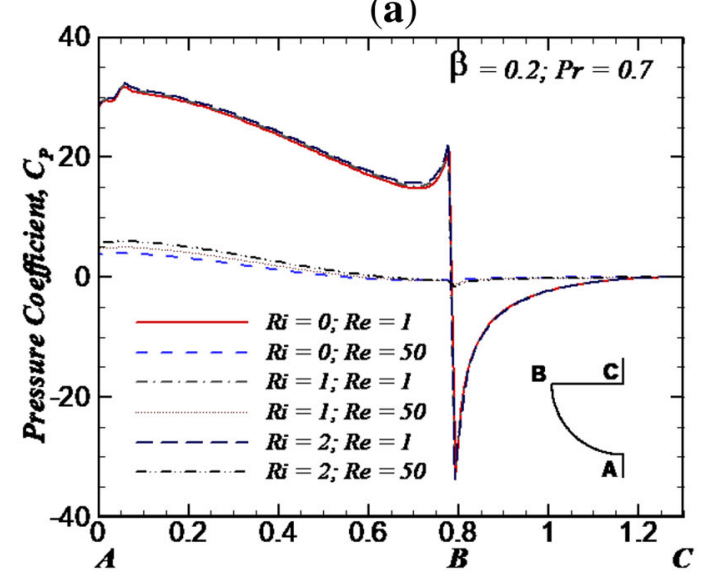

(c)

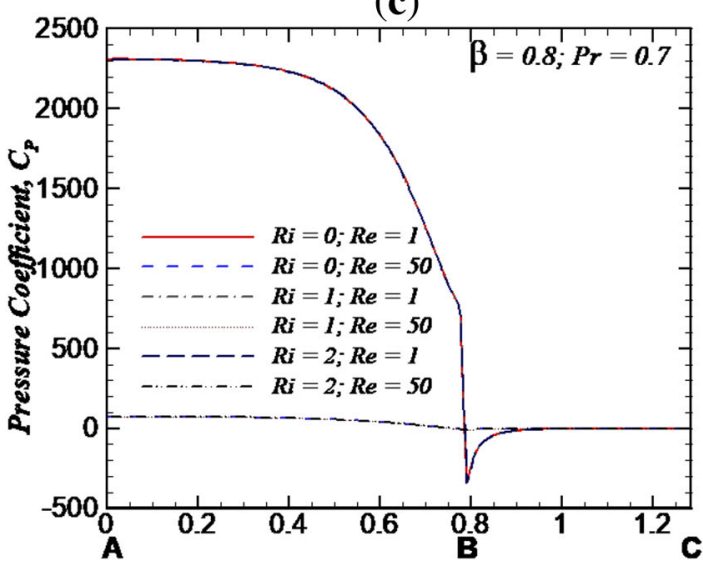

(b)

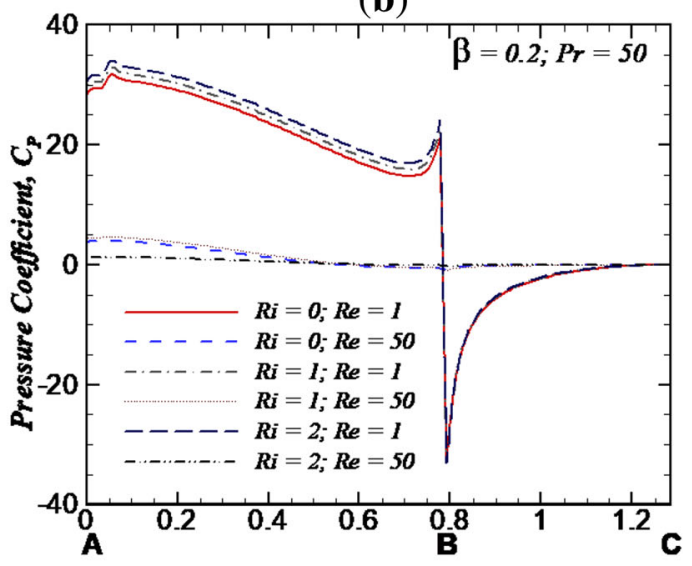

(d)

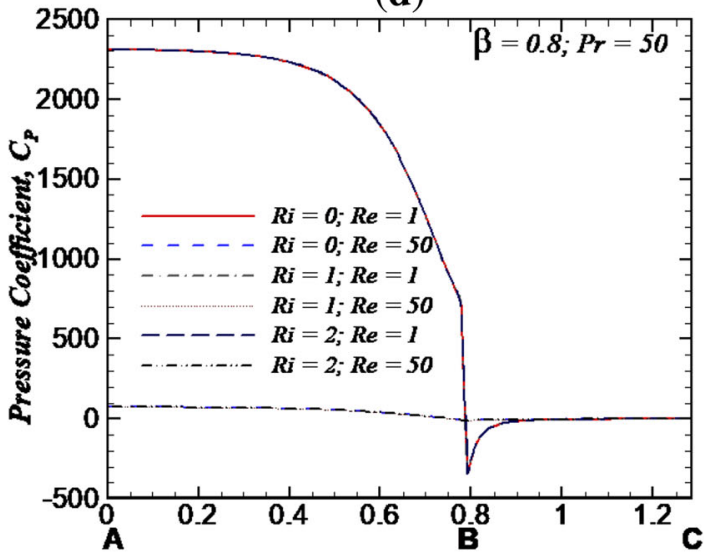

Figure 6. Variation of pressure coefficients $\left(C_{P}\right)$ at cylinder surface for different values of $R i$ and $R e$ at different sets of $\beta$ and $P r$ [(a) $\beta=0.2, \operatorname{Pr}=0.7$, (b) $\beta=0.2, \operatorname{Pr}=50$, (c) $\beta=0.8, \operatorname{Pr}=0.7$, (d) $\beta=0.8, \operatorname{Pr}=50]$.

initially increased due to increase of channel blockage ratio and afterwards decreased also. A similar kind of mixed effect of blockage ratio on wake size has been previously observed for wake behind a square cylinder [24].

4.1b Pressure coefficients distribution: More information on flow behaviour is collected from the surface variation of pressure coefficient $\left(C_{P}\right)$ over cylinder. The values of $C_{P}$ relate pressure recovery at any point of surface with respect to inlet pressure $\left(P_{\infty}\right)$. Figure 6 presents variation in values of pressure coefficients at cylinder surface for different values of Richardson number at different sets of values of $\operatorname{Pr}$ and $\beta$. It is clearly seen from figure 6 that the value of $C_{P}$ is maximum at the vicinity of vertex $\mathrm{A}$ and minimum at vertex $\mathrm{B}$. Further, a slight reverse for this minimum value is observed up to point $\mathrm{C}$ for all values of $R e$ and $R i$ studied. This may happen due to velocity increase from point $\mathrm{A}$ to $\mathrm{B}$ and decrease from point $B$ to point $C$. At all Richardson numbers, the values of $C_{P}$ have been high at $R e=1$ as compared with its values for $R e=50$. The reason behind this might be high velocity at $R e=50$. The value of pressure coefficient at curved surface $(\mathrm{AB})$ also gets larger with increase of $R i$ at $\beta=0.2$ for all values of $R e$. This behaviour is not observed at $\beta=0.8$, because, the flow area between cylinder and confined wall is less at increased blockage ratio of 0.8 and buoyant flow is insignificant. Figure 7 presents variation in values of pressure coefficients at cylinder surface for different blockage ratios. Figure 7 clearly shows that maximum and minimum values of $C_{P}$ widen due to increase in blockage ratio for each $R e, P r$ and $R i$ studied.

Figure 8 presents variation in values of pressure coefficients along the confinement wall length for different sets of $R e$ and $R i$. Figure 8 shows that pressure coefficient first decreases in the inlet domain (before cylinder) and has mixed patterns in the outlet domain (after cylinder) for different values of $\beta$ and $\operatorname{Pr}$ studied. Especially for $\beta=0.8$, the value of pressure coefficient suddenly drops at the end of inlet domain possibly due to high velocity observed. The magnitudes of values of pressure coefficients are reported to be comparatively high for value of $\beta=0.8$ as compared with $\beta=0.2$. For $R e=1$ and $\beta=0.2$, pressure coefficient upstream to cylinder decreases as Richardson number increases at $\operatorname{Pr}=0.7$, whereas it increases with rise of Richardson number at $\operatorname{Pr}=50$. For $\operatorname{Re}=1$ and $\beta=0.8$, no significant changes have been observed in values of 
(a)

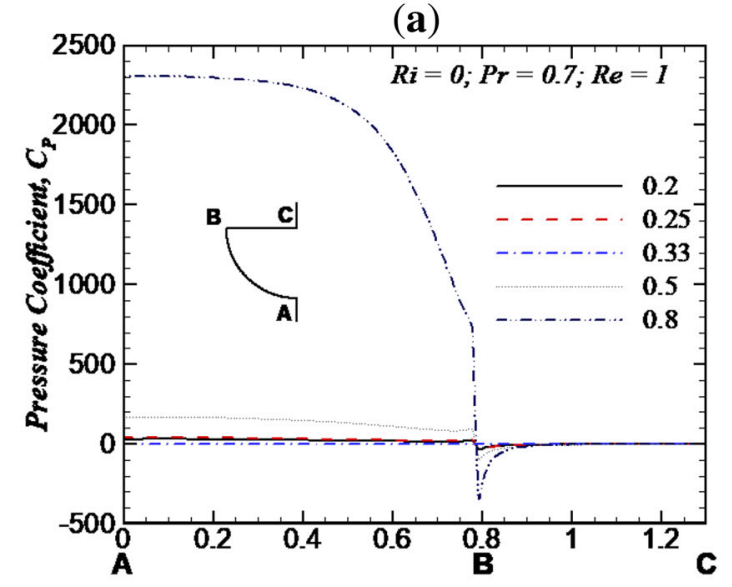

(c)

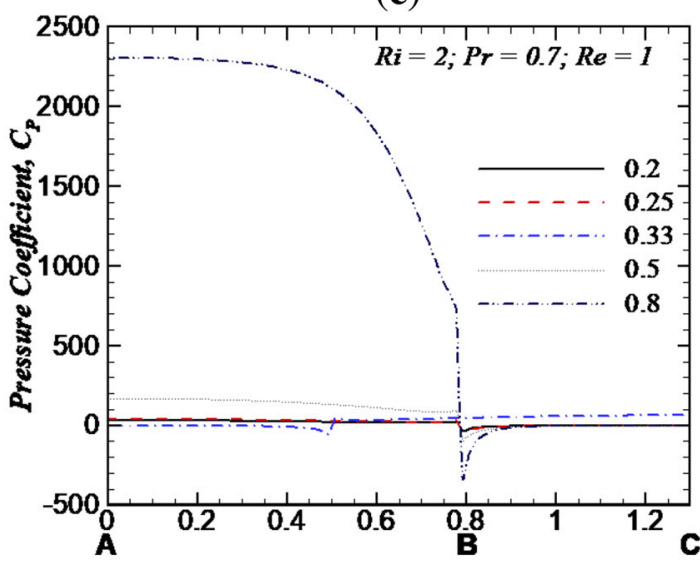

(b)

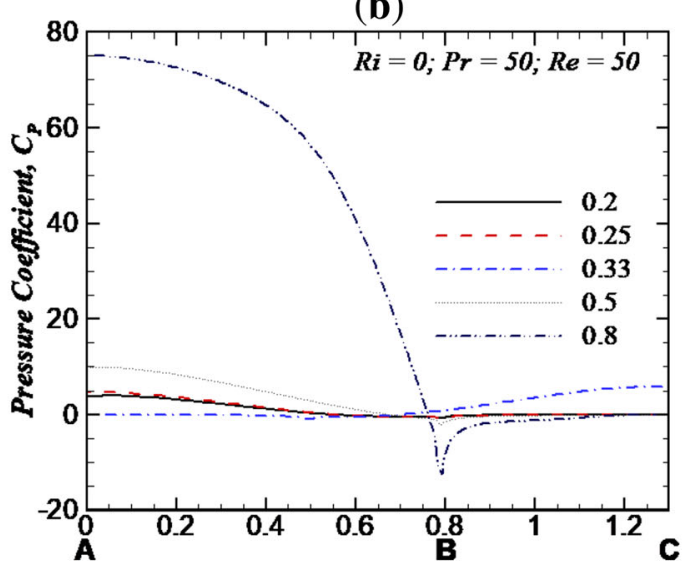

(d)

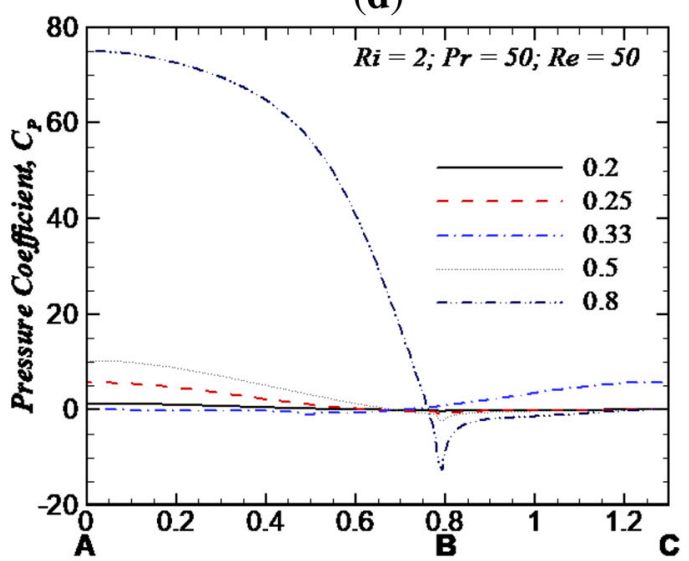

Figure 7. Variation of pressure coefficient $\left(C_{P}\right)$ at cylinder surface with different values of blockage ratio $(\beta)$ at different sets of $R i, P r$ and $\operatorname{Re}[(\mathbf{a}) \operatorname{Ri}=0, \operatorname{Pr}=0.7, \operatorname{Re}=1$, (b) $R i=0, \operatorname{Pr}=50, \operatorname{Re}=50,(\mathbf{c}) \operatorname{Ri}=2, \operatorname{Pr}=0.7, \operatorname{Re}=1,(\mathbf{d}) \operatorname{Ri}=2, \operatorname{Pr}=50, \operatorname{Re}=50]$.

pressure coefficient in inlet domain with increase in Richardson number at both $P r$ values 0.7 and 50. For $R e=50$ and $\beta=0.2$, the variation in values of pressure coefficient upstream to cylinder with Richardson number shows a reverse pattern as compared with $R e=1$. For $R e=50$ and $\beta=0.8$, values of pressure coefficient in inlet domain have no changes with increase in Richardson number at $P r=0.7$ and decrease with increase in $R i$ at $P r=50$. In the region downstream to the cylinder, the pressure coefficient has a mixed influence with increase in Richardson number at various conditions of $R e$ and $P r$ studied. For $R e=1$, the pressure coefficients increase due to rise in Richardson number for all values of $\beta$ and $\mathrm{Pr}$ studied. This effect is more pronounced at $\beta=0.2$ and/or $\operatorname{Pr}=0.7$. For $R e=50$, the pressure coefficients have no appreciable change with increase of Richardson number for all values of $\operatorname{Pr}$ and $\beta$ studied except increase in their values at $P r=0.7$ and $\beta=0.2$.

4.1c Drag coefficient and ratio of pressure drag to friction drag coefficient: Total drag force (in $y$-direction) and its coefficient on bluff body have contributions by components of normal and shear forces acting on the body. Effect of
Reynolds number on drag coefficient $\left(C_{D}\right)$ for different values of $\beta, R i$ and $\operatorname{Pr}$ on semi-circular cylinder surface is given in figure 9 . This figure clearly shows that value of $C_{D}$ continuously decreases due to increment in $R e$ for all sets of observations carried out. A similar behaviour of decrease in $C_{D}$ with increase in $R e$ has also been observed in some previous studies $[1,2,24,25,30]$. The rate of decrease in $C_{D}$ is observed to be higher for $R e<10$ as compared with $R e>10$, which may be due to higher contribution of viscous forces $(R e \leq 10)$ in total drag coefficients. Due to increase in Richardson number, value of $C_{D}$ increases at $\beta=0.2$ and all values of $R e$. The increase in value of $C_{D}$ with $R i$ is also reported in previous numerical works $[1,25,30]$. The increase in the drag coefficient with Richardson number is possibly due to rise in overall flow caused by buoyant effect. For blockage ratio $(\beta)=0.33$, the values of drag coefficient show complex behaviour and this complexity is more at higher value of $R i$ at all Reynolds number values. For $\beta=0.5$, the values of $C_{D}$ rise with increase in Richardson number at all Reynolds numbers, but the increase is less as compared with increase at low blockage ratio $(\beta=0.2)$. Moreover, at $\beta=0.8$, the drag 

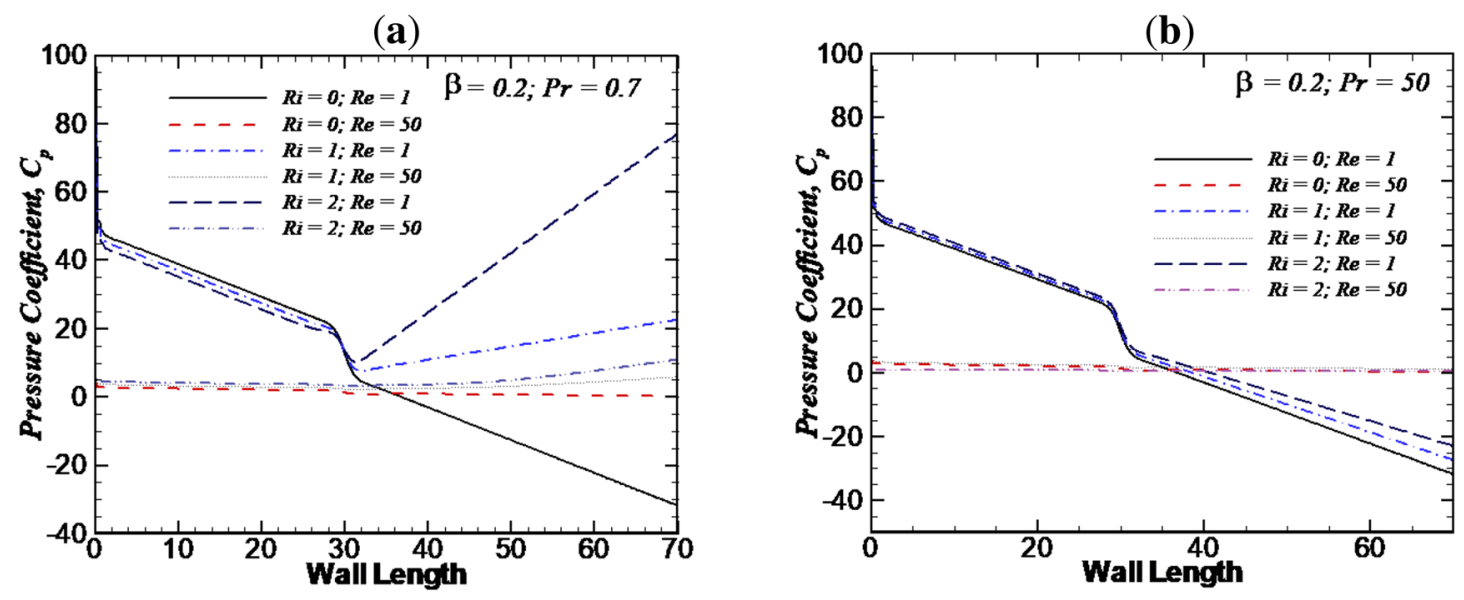

(c)

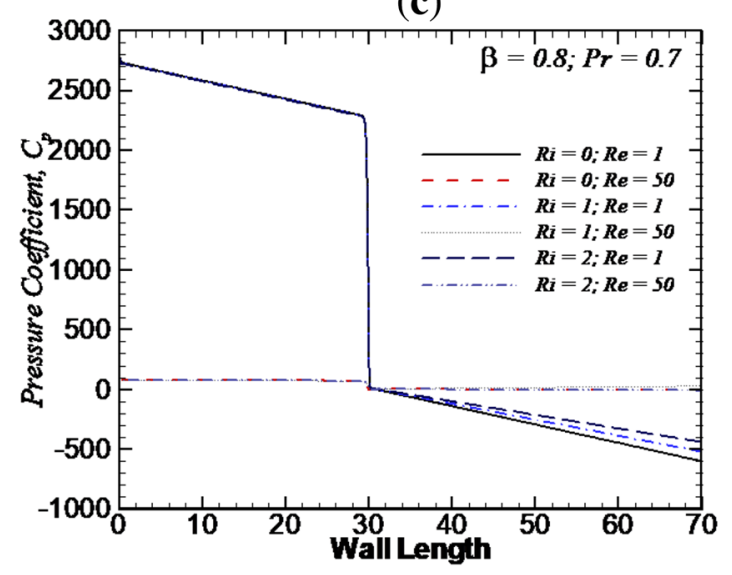

(d)

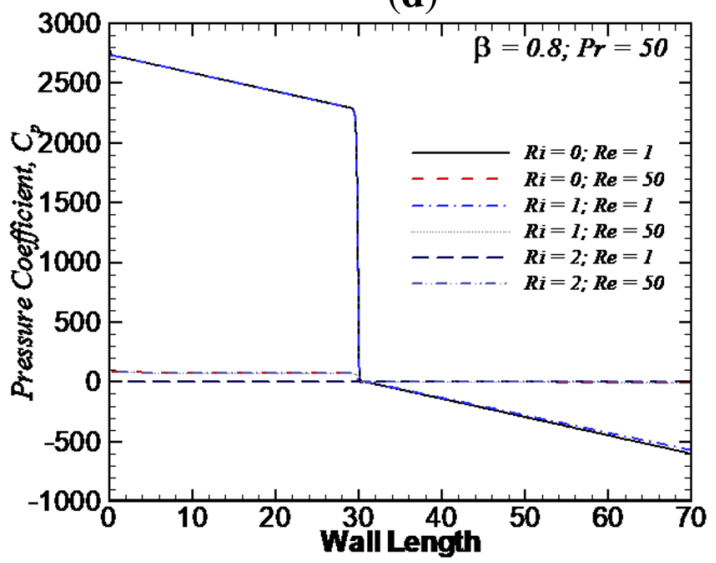

Figure 8. Variation of pressure coefficient $\left(C_{P}\right)$ at confinement wall surface for different values of $R e$ and $R i$ at different sets of $\beta$ and $\operatorname{Pr}[$ (a) $\beta=0.2, \operatorname{Pr}=0.7$, (b) $\beta=0.2, \operatorname{Pr}=50$, (c) $\beta=0.8, \operatorname{Pr}=0.7,(\mathbf{d}) \beta=0.8, \operatorname{Pr}=50]$.

coefficients are insignificantly changed with increase of Richardson number. It is already understood that for higher blockage ratio, area available for flow between cylinder and confined wall is less, buoyant flow is less significant and insignificant change in drag coefficient is observed at high blockage due to increase in $R i$. It is also observed from figure 9 that an increase in Prandtl number reduces the effect of $R i$ on $C_{D}$.

Moreover, the coefficient of total $\operatorname{drag}\left(C_{D}\right)$ is defined as sum of coefficients of pressure (form) drag $\left(C_{D P}\right)$ and coefficients of friction (viscous) drag $\left(C_{D F}\right)$. The relative importance of pressure drag to friction drag in total drag over bluff body is understood by the ratio of individual drag coefficients (i.e., $C_{D P} / C_{D F}$ ). The variation of $C_{D P} / C_{D F}$ ratio with value of $R e$ is presented in figure 10, at different values of $\beta, P r$ and $R i$. It is seen in figure 10 that the value of ratio of individual drag coefficients has been always greater than one for all cases considered; therefore, pressure drag has more contribution in total drag as compared with contribution of friction drag $[2,25]$. The $C_{D P} / C_{D F}$ ratio decreases with Reynolds number in the range of $R e<10$ and attains minimum value at $R e=10$ and further increases monotonically with $R e$. This implies that contribution of viscous drag, as compared with pressure drag, increases with $R e$ and becomes maximum at $R e=10$ and then decreases monotonically. This also tallies with steep decrease in $C_{D}$ values discussed earlier for $R e \leq 10$. Further, for $\beta=0.2, C_{D P} / C_{D F}$ ratio increases with rise in value of Richardson number for all $P r$. For $\beta=0.33, P r=0.7$, the values of $C_{D P} / C_{D F}$ ratio have insignificant changes and for $\beta=0.33, P r=50$, the values of $C_{D P} / C_{D F}$ ratio have mixed changing patterns with increase in value of $R i$. For $\beta=0.5,0.8$ and $P r=0.7$, the value of $C_{D P} / C_{D F}$ ratio increases and for $\beta=0.5,0.8$ and $P r=50$, the values of $C_{D P} / C_{D F}$ ratio have insignificant changes with rise in value of Richardson number. These variations of $C_{D P} / C_{D F}$ ratio at different blockage ratios with Richardson numbers also tally with results of total drag coefficients except at $\beta=0.5$, 0.8 and $\operatorname{Pr}=0.7$.

\subsection{Heat transfer description}

4.2a Isotherm profiles: The flow field in the vicinity of semi-circular cylinder directly relates the behaviour of isotherm contours, and isotherm profiles ultimately show 

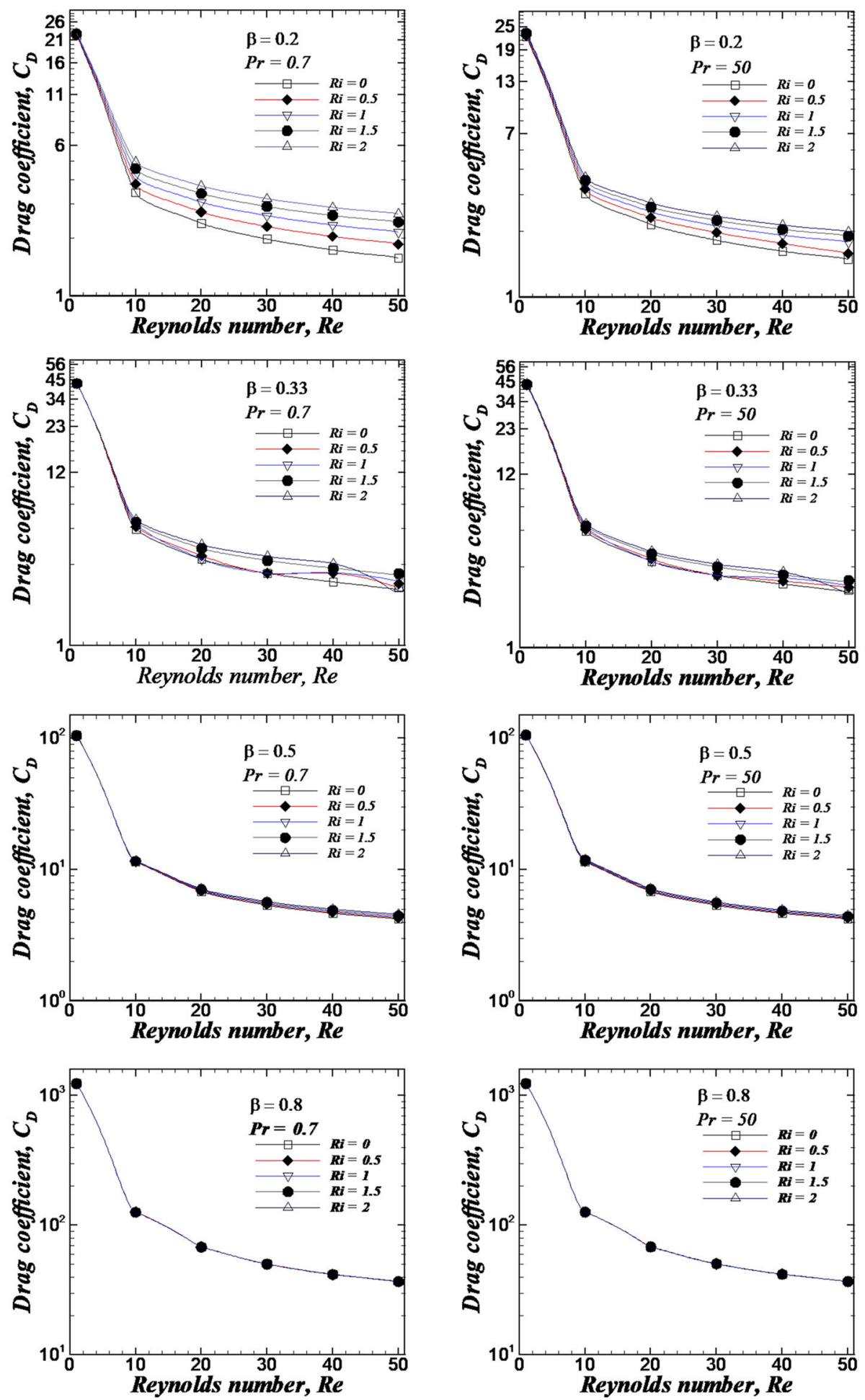

Figure 9. Variation of drag coefficients with $R e$ at different values of $\beta, \operatorname{Pr}$ and $R i$.

the heat transfer fields. It is well known that both crowding and spreading of isotherms are governed by local and average Nusselt numbers. The isotherm contours for the present set of conditions are shown in right half portions of figures 3-5. For all cases, thinner thermal boundary layers are observed on the curved side of cylinder than on the flat portion of cylinder because the curved surface of cylinder faces the incoming flow. This shows enhanced heat transfer from the curved side of semi-circular cylinder and is similar to previously 

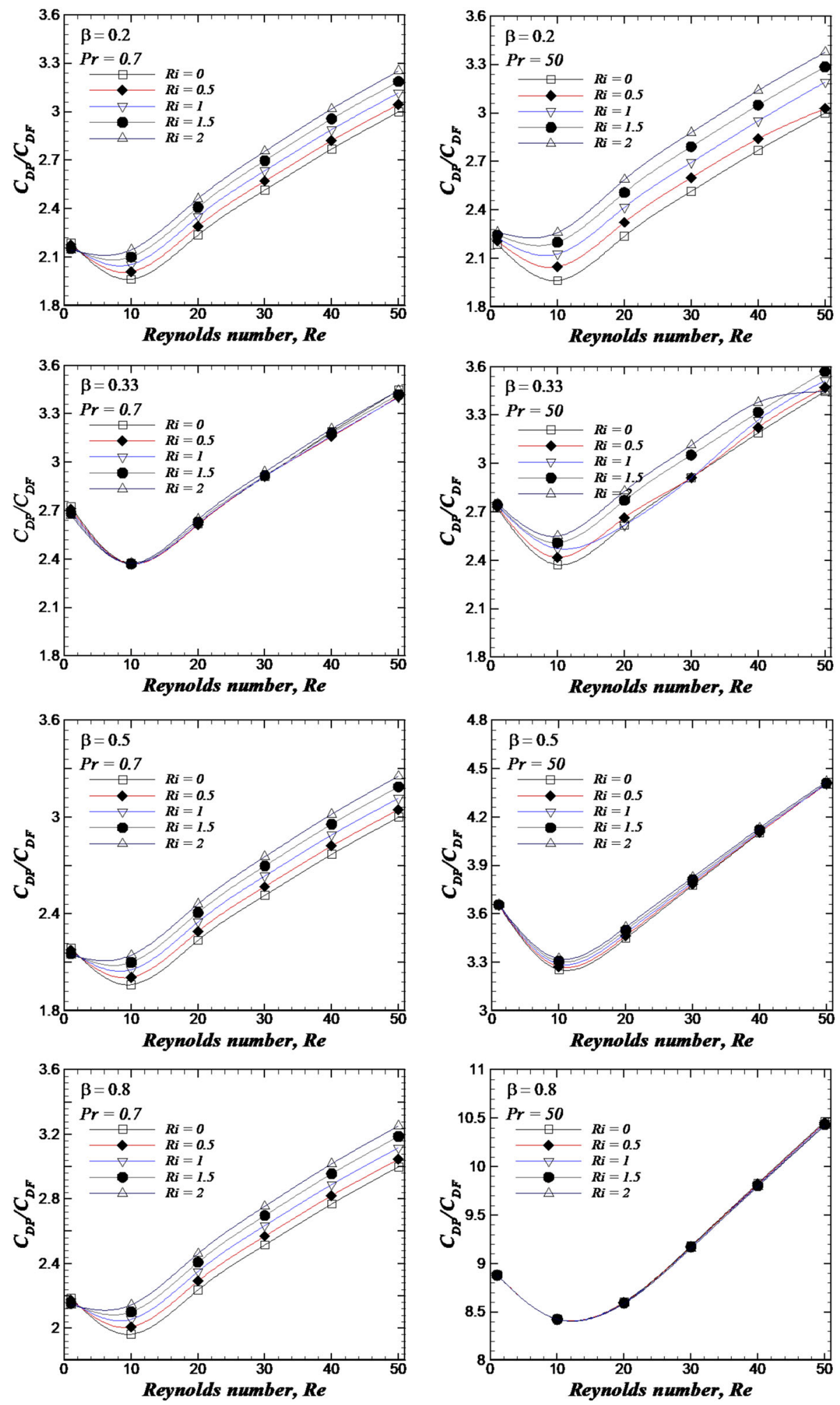

Figure 10. Variation in ratio of individual drag coefficients $\left(C_{D P} / C_{D F}\right)$ with $R e$ at different values of $R i, \operatorname{Pr}$ and $\beta$.

reported results in literature [24]. In figures 3-5, clustering of isotherms around the semi-circular cylinder is observed to be higher at $R e=50$ as compared with $R e=1$ for all sets of $\operatorname{Pr}, R i$ and $\beta$ studied. The high clustering of isotherms shows high thermal gradients in close proximity to the cylinder. Moreover, for $R e=1$, temperature 
(a)

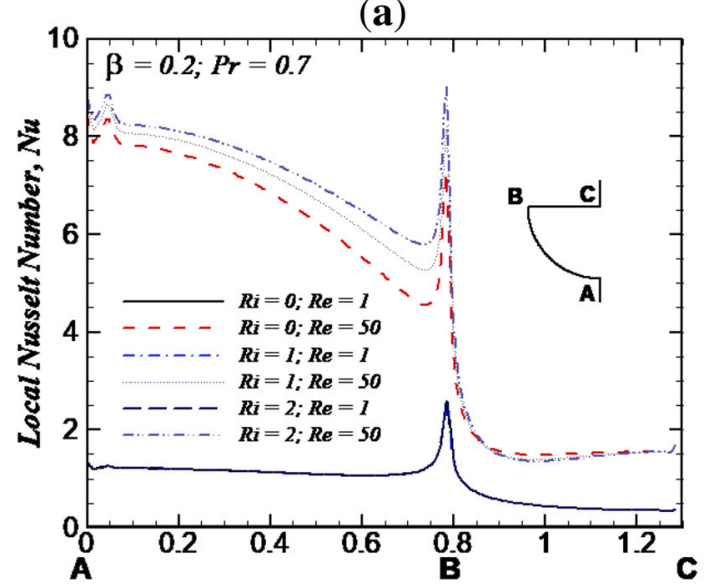

(c)

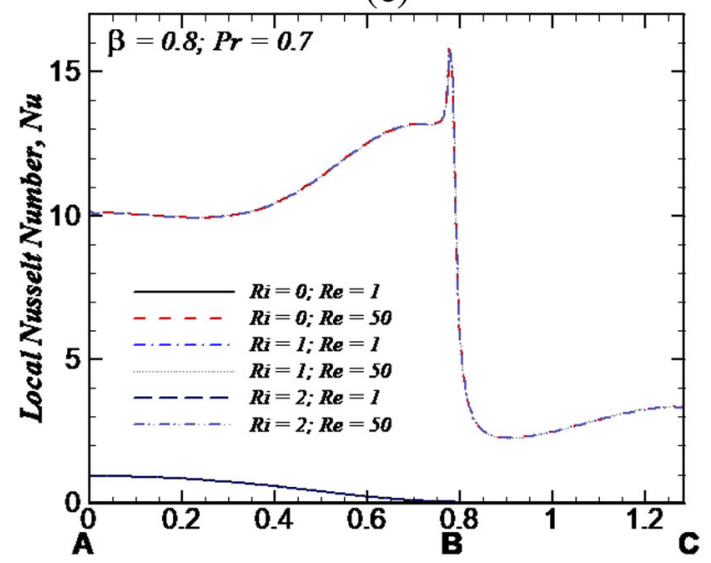

(b)

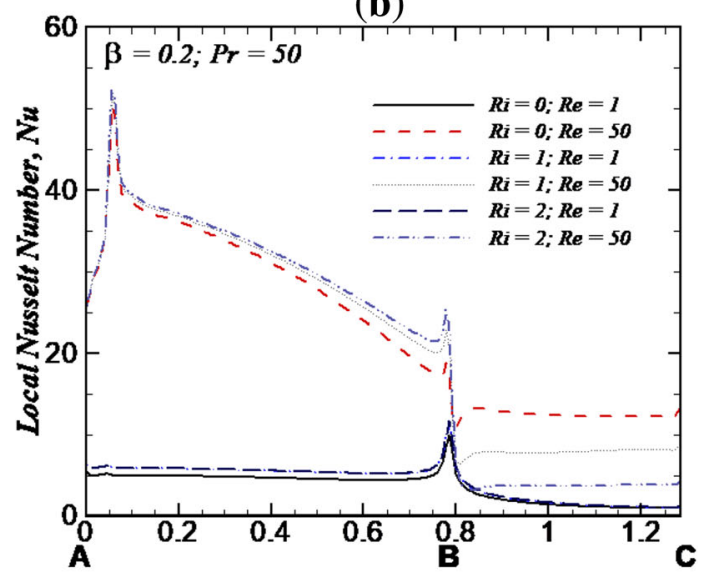

(d)

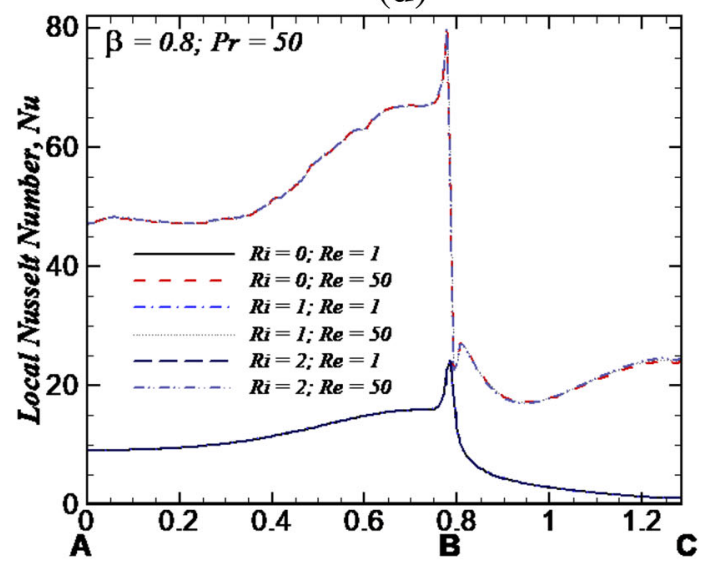

Figure 11. Variation of local Nusselt number along cylinder surface at different values of $R i$ and $R e$ at different sets of $\beta$ and $P r$ [(a) $\beta=0.2, \operatorname{Pr}=0.7$, (b) $\beta=0.2, \operatorname{Pr}=50$, (c) $\beta=0.8, \operatorname{Pr}=0.7$, (d) $\beta=0.8, \operatorname{Pr}=50]$.

gradients are seen to be high at corners as compared with flat surface of cylinder but this phenomenon is reversed for $R e=50$. Both of these observations can be explained by the domination of inertial forces and formation of wakes at flat side of cylinder at $R e=50$. Further, lateral width of isotherms is reduced at $R e=50$ as compared with $R e=1$. This is because of the domination of heat transfer by convection at $R e=50$ as compared with heat transfer by conduction at $R e=1$ [24]. The increase of Prandtl number in the range of 1-50 also increases the temperature gradients near cylinder at all sets of $R e, R i$ and $\beta$ studied. This behaviour is observed due to shrinkage of thermal boundary layer at higher values of $P r$. Further, for $\beta=0.2$, increase in value of buoyancy $(=R i)$ has no appreciable effect on isotherms at $P r=0.7$, but higher temperature gradients have been observed at $P r=50$ due to increase of buoyancy. This effect of buoyancy is similar to previous results reported in literature for an unconfined semi-circular cylinder [25] as well as confined cylinder of circular or square cross-section [20, 24]. Further investigation of figure 4 for $\beta=0.33$ shows no changes of isotherms with increase in $R i$ for all cases studied. At
$R e=50$ and $P r=50$, mixed effects are observed due to increase in Richardson number. For $\beta=0.8$, increase in values of $R i$ has no effects on isotherms for all cases studied here. The high blockage ratio tries to supress the isotherms strongly, and increase in Richardson number is not observed to have any further congestion among isotherms. This behaviour tallies with the isotherm behaviour observed for heated square cylinders at high blockage ratio of 0.5 [1]. This discussion shows that increase in value of $R i$ affects isotherms only at low blockage ratio $(\beta=0.2,0.33)$ in a mixed manner and it shows complex behaviour with interplay of $R e, P r, R i$ and $\beta$. Moreover, as blockage ratio is increased, lower temperature gradients are observed around the cylinder at all values of $R e, P r$ and $R i$. The reason for this might be the fact that as blockage ratio is more, velocity and mass flow of fluid around the cylinder decrease. Less flow of fluid around the cylinder is responsible for low heat transfer and low temperature gradients. These isotherm profiles have similar behaviour as compared to square cylinders in literature [24] in the particular range of $\beta=0.3-0.5$ at $\operatorname{Re}=20$ and $\operatorname{Pr}=50$ only. 
(a)

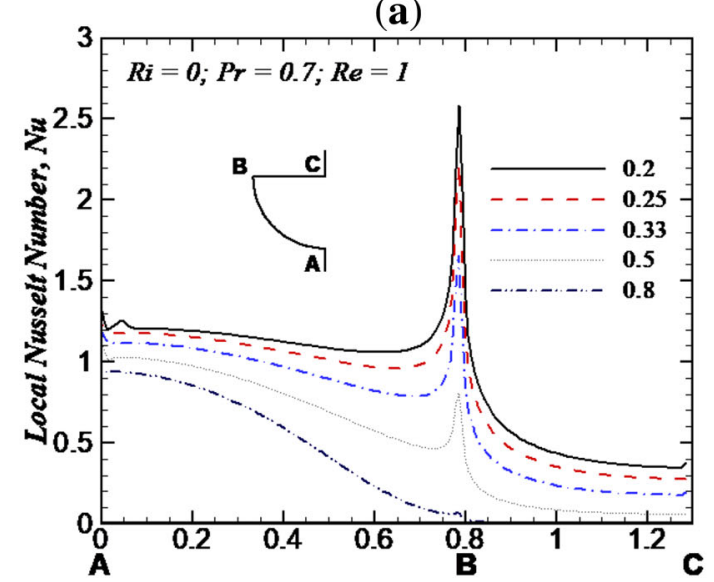

(c)

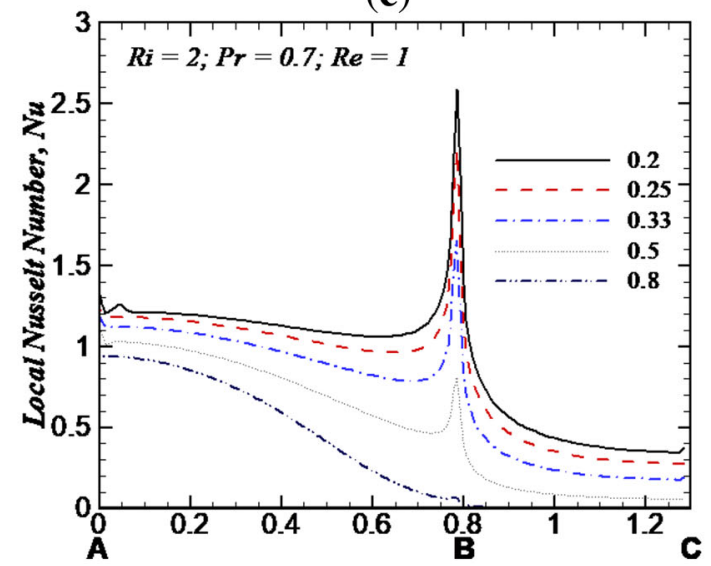

(b)

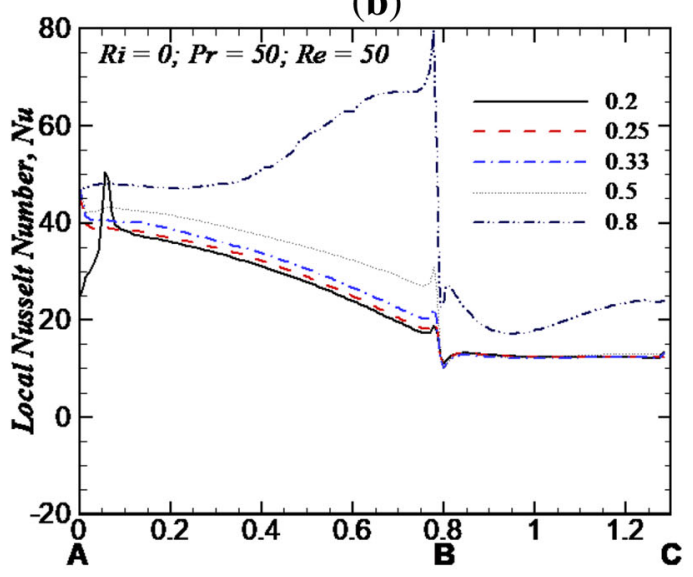

(d)

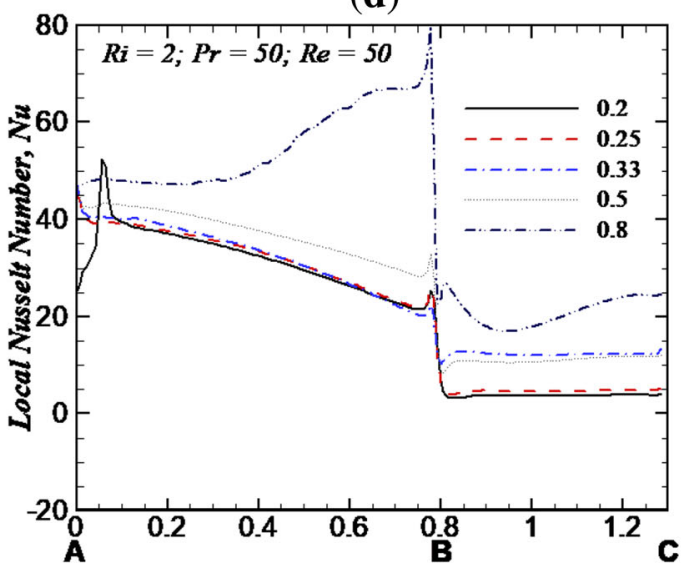

Figure 12. Variation of local Nusselt number along cylinder surface at different values of $\beta$ with different sets of $R i, P r$ and $R e$ [(a) $R i=0, \operatorname{Pr}=0.7, \operatorname{Re}=1$, (b) $R i=0, \operatorname{Pr}=50, \operatorname{Re}=50,(\mathbf{c}) \operatorname{Ri}=2, \operatorname{Pr}=0.7, \operatorname{Re}=1$, (d) $\operatorname{Ri}=2, \operatorname{Pr}=50, \operatorname{Re}=50]$.

4.2b Local Nusselt number $(\mathrm{Nu})$ : A detailed distribution of values of $N u$ over cylinder surface is presented in figure 11, for different sets of $R e$ and $R i$ at different combinations of $\beta$ and $\mathrm{Pr}$. This shows that the values of $\mathrm{Nu}$ are higher at curved surface compared with its values at flat surface for all conditions. The value of $N u$ is increased due to rise of $R e$ for all conditions of $\operatorname{Pr}, \beta$ and $R i$ studied. At $R e=1$, local Nusselt number has no appreciable change due to increase in Richardson number in all cases studied. For $R e=50$, value of $N u$ increases due to rise in value of $R i$ at all cases but the effect is much pronounced at small values of both $\mathrm{Pr}$ and $\beta$ (figure 11). The variations of $\mathrm{Nu}$ along surface $(\mathrm{ABC})$ of cylinder are presented in figure 12 for different blockage ratios at different sets of $R e, \operatorname{Pr}$ and $R i$. It is observed in this figure that values of local Nusselt numbers increase due to increase in blockage ratio for high values of Peclect number $(=2500)$, but the phenomenon is reversed for low values of Peclect number $(=0.7)$. This distinct phenomenon is observed due to interplay of $\mathrm{Re}, \mathrm{Pr}$ and $\beta$. In particular, effective flow rate increases with increase in $\beta$ and a thick thermal boundary is observed due to low Peclect number. Therefore, local heat transfer is reduced at the surface of the cylinder at such low Peclect number and high blockage ratio. For all cases of Peclect numbers, a sharp peak of local Nusselt number has also been observed at point B of cylinder surface. Point B has this kind of peak value of Nusselt number due to a geometrical singularity [24]. The maximum value of local Nusselt number has also been observed at corner points in other confined heat transfer studies [30] also.

4.2c Average Nusselt number $\left(N u_{\text {avg }}\right)$ : In daily life applications, heat transfer coefficient is used for engineering calculations at particular sets of $R i, \operatorname{Re}, \operatorname{Pr}$ and $\beta$. The same coefficient may be easily obtained from the magnitude of $N u_{\text {avg }}$ at the same conditions. The representative variation in values of $N u_{\text {avg }}$ with $R e$ at separate sets of $R i, \operatorname{Pr}$ and $\beta$ is given in figure 13. The values of $N u_{\text {avg }}$ are observed to increase due to increase in value of $R e$ and/or $\mathrm{Pr}$, as expected for all settings. The value of $N u_{a v g}$ also increases due to increase of Richardson number at all Reynolds numbers except $R e=1$ and this effect is more pronounced 

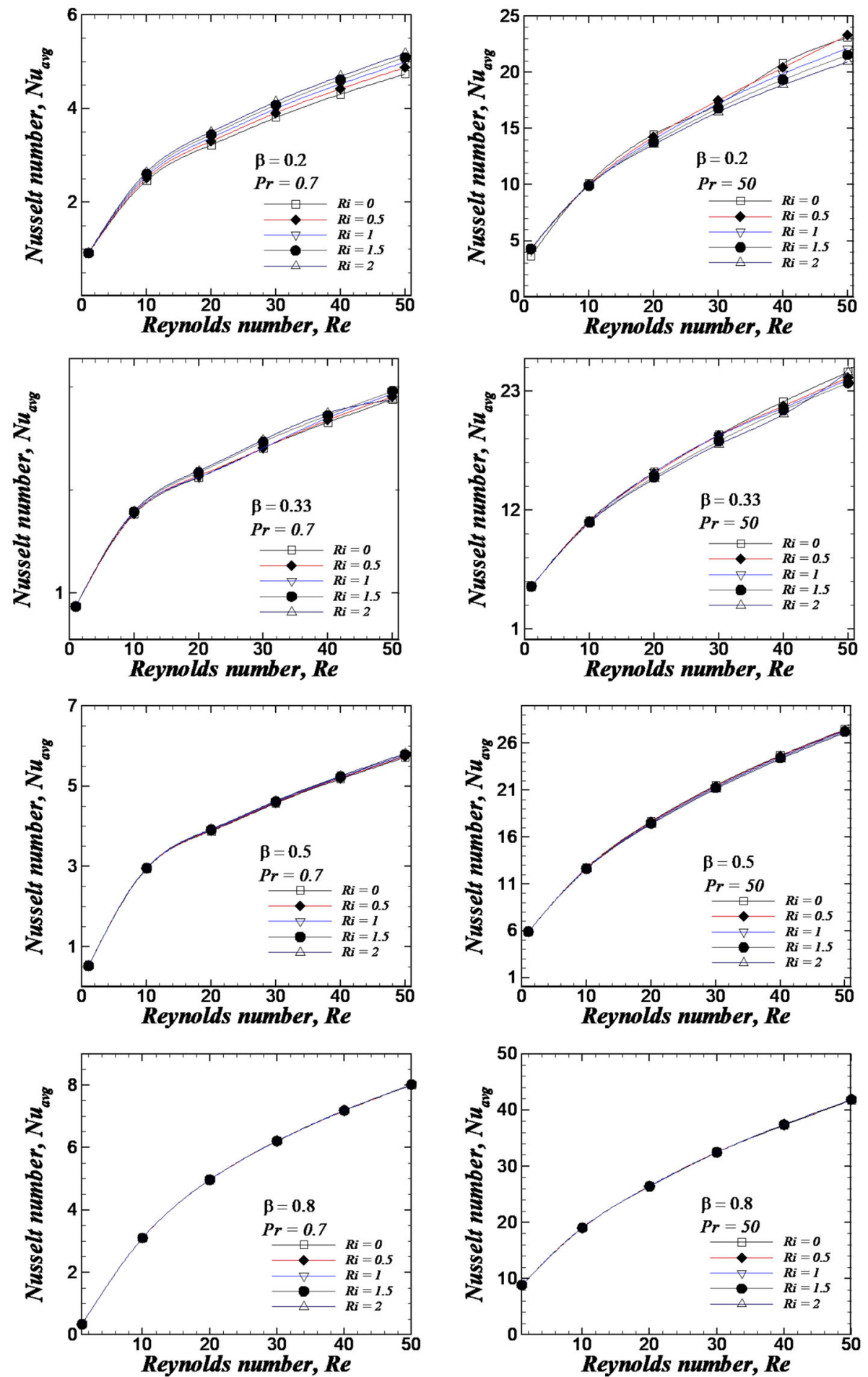

Figure 13. Variation of $N u_{\text {avg }}$ at the surface of the semi-circular cylinder for $\operatorname{Pr}=0.7,50, \beta=0.2-0.8$ and $R i=0-2$.

at large $R e$ and/or low $\beta$. The increase in $N u_{\text {avg }}$ with increase in value of $R i$ is also reported in a similar study [30] for square cylinders. The values of $N u_{\text {avg }}$ at $\operatorname{Pr}=50$ are found to be higher compared with values at $P r=0.7$ for other identical conditions.

\section{Conclusion}

The current work presents study of flow and thermal fields for Newtonian fluids around a hot isothermal semi-circular cylinder, inside a confined channel. This study has been 
performed for parameter ranges $1 \leq R e \leq 50,0.7 \leq P r$ $\leq 50,0 \leq R i \leq 2$ and $0.2 \leq \beta \leq 0.8$. Different results of flow parameters like streamlines, pressure coefficients and individual and total drag coefficients have been presented and discussed. Moreover, isotherms, local and average heat transfer coefficients are also discussed to get insight of heat transfer phenomena. The flow is found to be steady at all values of $R e$ and is observed to be either attached to the cylinder or separated with wake formation depending on $R e$. The maximum values of pressure coefficient is observed near the front stagnation point and its minimum value is observed at a point at the rear side of the cylinder (depending on blockage ratio of confinement). The values of total drag coefficient increased with increase in blockage ratio of confinement and also with increase in Richardson number but only at lower blockage ratio. This enhances heat transfer from curved side of semi-circular cylinder. Isothermal lines are found to be more crowded to the cylinder with increase in Reynolds number $(R e)$ or Prandtl number $(P r)$ and/or decrease in blockage ratio $(\beta)$ and Richardson number only at high $\operatorname{Re}(\approx 50)$. The value of average Nusselt number is observed to increase with increase in Reynolds number and Prandtl number. It is seen for all cases (except $R e=1$ ) that average Nusselt number increases due to increase of Richardson number, which is also more pronounced at lower blockage ratio. The average Nusselt number also increased with increase in Prandtl number at all otherwise identical conditions. The present work is executed as a preliminary effort towards design of a novel heat exchanger as a future work.

\footnotetext{
Nomenclature

$C_{D} \quad$ drag coefficient at the surface of semi-circular cylinder (dimensionless)

$C_{D F} \quad$ friction (viscous) drag coefficient at the surface of semi-circular cylinder (dimensionless)

$C_{D P} \quad$ pressure drag coefficient at the surface of semicircular cylinder (dimensionless)

$c_{p} \quad$ specific heat capacity of the fluid $(\mathrm{J} / \mathrm{kg} \mathrm{K})$

$C_{P} \quad$ pressure coefficient at the surface of semi-circular cylinder (dimensionless)

$D \quad$ diameter of semi-circular cylinder (m)

$F_{D} \quad$ drag force per unit length of semi-circular cylinder $(\mathrm{N} / \mathrm{m})$

$F_{D P} \quad$ pressure drag force per unit length of semi-circular cylinder $(\mathrm{N} / \mathrm{m})$

$F_{D F} \quad$ friction (viscous) drag force per unit length of semicircular cylinder $(\mathrm{N} / \mathrm{m})$

$g \quad$ gravitational acceleration $\left(\mathrm{m} / \mathrm{s}^{2}\right)$

$h_{\text {avg }}$ average heat transfer coefficient at surface of semicircular cylinder $\left(\mathrm{W} / \mathrm{m}^{2} \mathrm{~K}\right)$

Gr Grashof number $\left[=g \beta_{\mathrm{V}} \Delta T D^{3} \rho^{2} / \mu^{2}\right]$ (dimensionless)

$k \quad$ thermal conductivity of the fluid (W/m K)
}

$L \quad$ gap between two adiabatic confining walls (m)

$M, N$ distance (m)

$n_{s} \quad$ unit vector normal to cylinder surface

$P \quad$ pressure $(\mathrm{Pa})$

$\mathrm{Pe} \quad$ Peclet number $[=\operatorname{Re} . P r]$ (dimensionless)

$P_{s} \quad$ static pressure at cylinder surface $(\mathrm{Pa})$

$P_{\infty} \quad$ fluid pressure at inlet section $(\mathrm{Pa})$

$\operatorname{Pr} \quad$ Prandtl number $\left[=c_{p} \mu / k\right]$ (dimensionless)

Re Reynolds number [ $\left.=D V_{\infty} \rho / \mu\right]$ (dimensionless)

$S \quad$ surface area of cylinder $\left(\mathrm{m}^{2}\right)$

$T_{w} \quad$ wall temperature of the cylinder $(\mathrm{K})$

$T \quad$ fluid absolute temperature $(\mathrm{K})$

$T_{\infty} \quad$ fluid temperature at the inlet section (K)

$U \quad$ fluid velocity in $X$-direction $(\mathrm{m} / \mathrm{s})$

$V \quad$ fluid velocity in $Y$-direction $(\mathrm{m} / \mathrm{s})$

$V_{\max }$ maximum velocity at inlet of confinement $(\mathrm{m} / \mathrm{s})$

$V_{\infty} \quad$ average velocity at inlet of confinement $(\mathrm{m} / \mathrm{s})$

$X, Y \quad$ Cartesian co-ordinates $(\mathrm{m})$

\section{Greek symbols}

$\beta \quad$ blockage ratio of confinement $[=D / L]$

(dimensionless)

$\beta_{\mathrm{V}} \quad$ coefficient of thermal volumetric expansion of fluid $\left(\mathrm{K}^{-1}\right)$

$\theta \quad$ fluid temperature (dimensionless)

$\rho \quad$ fluid density $\left(\mathrm{kg} / \mathrm{m}^{3}\right)$

$\rho_{\infty} \quad$ fluid density at temperature of $T_{\infty}\left(\mathrm{kg} / \mathrm{m}^{3}\right)$

$\mu \quad$ dynamic viscosity of fluid $(\mathrm{kg} / \mathrm{m} \mathrm{s})$

$\delta \quad$ size of grid element at surface of semi-circular cylinder (m)

\section{References}

[1] Dhiman A, Sharma N and Kumar S 2014 Buoyancy-aided momentum and heat transfer in a vertical channel with a built-in square cylinder. Int. J. Sustain. Energy 33(5): 963-984

[2] Kumar A and Dhiman A 2015 Laminar flow and heat transfer phenomena across a confined semicircular bluff body at low reynolds numbers. Heat Transf. Eng. 36(18): 1540-1551

[3] Kumar A, Dhiman A and Baranyi L 2015 CFD analysis of power-law fluid flow and heat transfer around a confined semi-circular cylinder. Int. J. Heat Mass Transf. 82: 159-169

[4] Chandra A and Chhabra R P 2011 Flow over and forced convection heat transfer in Newtonian fluids from a semicircular cylinder. Int. J. Heat Mass Transf. 54: 225-241

[5] Karniadakis G E 1988 Numerical simulation of forced convection heat transfer from a cylinder in crossflow. Int. J. Heat Mass Transf. 31(1): 107-118

[6] Zdravkovich M M 1997 Flow around circular cylinders, vol. 1: Fundamentals. New York: Oxford University Press

[7] Zdravkovich M M 2003 Flow around circular cylinders, vol. 2: Applications. New York: Oxford University Press

[8] Chhabra R P 2011 Fluid flow and heat transfer from circular and non-circular cylinders submerged in non-Newtonian fluid. Adv. Heat Transf. 43: 289-417 
[9] Oosthuizen P H and Madan S 1970 Combined convective heat transfer from horizontal cylinders in air. J. Heat Transf. 92(1): 194-196

[10] Oosthuizen P H and Madan S 1971 The effect of flow direction on combined convective heat transfer from cylinders to air. J. Heat Transf. 93: 240-242

[11] Singh S K, Panigrahi P K and Muralidhar K 2007 Effect of buoyancy on the wakes of circular and square cylinders: a schlieren-interferometric study. Exp. Fluids 43: 101-123

[12] Nada S A, El-Batsh H and Moawed M 2007 Heat transfer and fluid flow around semi-circular tube in cross flow at different orientations. Heat Mass Transf. 43: 1157-1169

[13] Badr H M 1983 A theoretical study of laminar mixed convection from a horizontal cylinder in a cross stream. Int. J. Heat Mass Transf. 26: 639-653

[14] Badr H M 1984 Laminar combined convection from a horizontal cylinder-parallel and contra flow regimes. Int. J. Heat Mass Transf. 27(1): 15-27

[15] Badr H M 1985 On the effect of flow direction on mixed convection from a horizontal cylinder. Int. J. Numer. Methods Fluids 5: 1-12

[16] Chang K S and Sa J Y 1990 The effect of buoyancy on vortex shedding in the near wake of a circular cylinder. $J$. Fluid Mech. 220: 253-266

[17] Rashid A and Hasan N 2011 Vortex-shedding suppression in mixed convective flow past a heated square cylinder. Int. J. Mech. Aerosp. Ind. Mechatron. Manuf. Eng. 5(6): 953-961

[18] Sharma N, Dhiman A K and Kumar S 2012 Mixed convection flow and heat transfer across a square cylinder under the influence of aiding buoyancy at low Reynolds numbers. Int. J. Heat Mass Transf. 55: 2601-2614

[19] Farouk B and Guceri S I 1982 Natural and mixed convection heat transfer around a horizontal cylinder within confining walls. Numer. Heat Transf. 5: 329-341

[20] Ho C J, Wu M S and Jou J B 1990 Analysis of buoyancyaided convection heat transfer from a horizontal cylinder in a vertical duct at low Reynolds number. Warme Stofffubertrag. 25: $337-343$

[21] Singh S, Biswas G and Mukhopadhyay A 1998 Effect of thermal buoyancy on the flow through a vertical channel with a built-in circular cylinder. Numer. Heat Transf. A 34: 769-789

[22] Gandikota G, Amiroudine S, Chatterjee D and Biswas G 2010 The effect of aiding/opposing buoyancy on two dimensional laminar flow across a circular cylinder. Numer. Heat Transf. A 58: 385-402

[23] Chatterjee D and Mondal B 2012 Effect of thermal buoyancy on the two-dimensional upward flow and heat transfer around a square cylinder. Heat Transf. Eng. 33(12): 1063-1074

[24] Sharma N, Dhiman A and Kumar S 2013 Non-newtonian power-law fluid flow around a heated square bluff body in a vertical channel under aiding buoyancy. Numer. Heat Transf. A 64: 777-799

[25] Chandra A and Chhabra R P 2012 Mixed convection from a heated semi-circular cylinder to power-law fluids in the steady flow regime. Int. J. Heat Mass Transf. 55: 214-234

[26] Kumar A, Dhiman A and Baranyi L 2016 Fluid flow and heat transfer around a confined semi-circular cylinder: onset of vortex shedding and effects of Reynolds and Prandtl numbers. Int. J. Heat Mass Transf. 102: 417-425

[27] Bird R B, Stewart W E and Lightfoot E N 2002 Transport phenomena, 2nd ed. New York: Wiley

[28] Anantheswaran R C and Rao M A 1985 Heat transfer to model Newtonian liquid foods in can during end-over-end rotation. J. Food Eng. 4: 1-19

[29] Cengel Y A and Ghajar A J 2016 Heat and mass transfer: fundamental and applications, 5th ed. New Delhi: McGraw Hill Education (India) Private Limited

[30] Chatterjee D 2010 Mixed convection heat transfer from tandem square cylinders in a vertical channel at low Reynolds numbers. Numer. Heat Transf. A 58: 740-755 